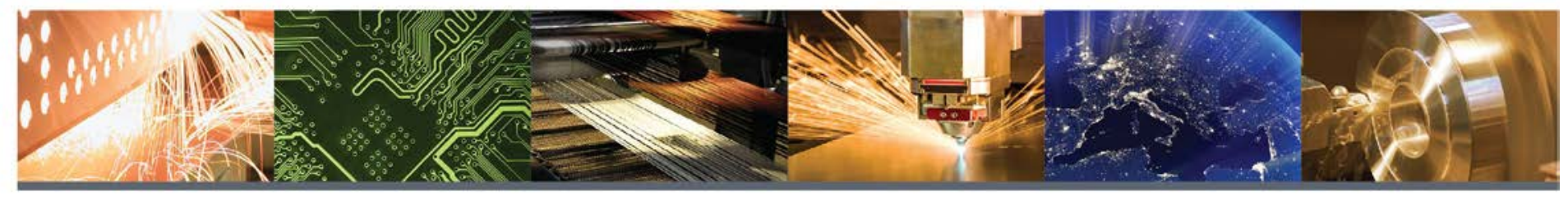

\title{
Mapping the Supply Chain for Room Air Conditioning Compressors
}

Scott Nicholson and Chuck Booten National Renewable Energy Laboratory

CEMAC is operated by the Joint Institute for Strategic Energy Analysis for the U.S. Department of Energy's Office of Energy Efficiency and Renewable Energy.

Technical Report

NREL/TP-6A20-73206

May 2019 


\section{Mapping the Supply Chain for Room Air Conditioning Compressors}

Scott Nicholson and Chuck Booten

National Renewable Energy Laboratory

CEMAC is operated by the Joint Institute for Strategic Energy Analysis for the U.S. Department of Energy's Office of Energy Efficiency and Renewable Energy.

Clean Energy Manufacturing Analysis Center 15013 Denver West Parkway Golden, CO 80401 303-275-3000

www.manufacturingcleanenergy.org
Technical Report

NREL/TP-6A20-73206

May 2019

Contract No. DE-AC36-08GO28308 


\section{NOTICE}

This work was authored by the National Renewable Energy Laboratory, operated by Alliance for Sustainable Energy, LLC, for the U.S. Department of Energy (DOE) under Contract No. DE-AC36-08G028308. Funding provided by Kigali Cooling Efficiency Program. The views expressed herein do not necessarily represent the views of the DOE or the U.S. Government.

This report is available at no cost from the National Renewable Energy Laboratory (NREL) at www.nrel.gov/publications.

U.S. Department of Energy (DOE) reports produced after 1991 and a growing number of pre-1991 documents are available free via www.OSTI.gov.

Cover Photos: (left to right) iStock 2225189; iStock 16687273; Oak Ridge National Laboratory; iStock 24304597; iStock 26005993; iStock 2069560

NREL prints on paper that contains recycled content. 


\section{Acknowledgments}

We would like to thank the Kigali Cooling Efficiency Program for providing funding for this analysis. In particular, we would like to thank Gabby Dreyfus for providing guidance and connecting us with cooling industry experts whose perspectives were essential in developing this report. We would also like to thank Samira Elkhamlichi and the rest of the World Bank team for inviting us to present preliminary findings from this work at the 2018 International Sustainable Cooling Conference and $5^{\text {th }}$ Annual $\mathrm{CO}_{3} \mathrm{OL}$ Workshop in Washington D.C. 


\section{Nomenclature or List of Acronyms}

$\begin{array}{ll}\text { BEE } & \text { Bureau of Energy Efficiency } \\ \text { CEMAC } & \text { Clean Energy Manufacturing Analysis Center } \\ \text { GMCC } & \text { Guangdong Meizhi Compressor Company } \\ \text { GWP } & \text { global warming potential } \\ \text { HCFC } & \text { hydrochlorofluorocarbon } \\ \text { HFC } & \text { hydrofluorocarbon } \\ \text { HS } & \text { harmonized system } \\ \text { kW } & \text { kilowatts } \\ \text { MEPS } & \text { minimum efficiency performance standard } \\ \text { MLF } & \text { Multilateral Fund for the Implementation of the Montreal Protocol } \\ \text { NREL } & \text { National Renewable Energy Laboratory } \\ \text { POE } & \text { polyolester } \\ \text { PVE } & \text { polyvinyl ether } \\ \text { R-22 } & \text { chlorodifluoromethane } \\ \text { R-290 } & \text { propane } \\ \text { R-32 } & \text { difluoromethane } \\ \text { RAC } & \text { room air conditioning } \\ \text { THACOM } & \text { Thai Compressor Manufacturing Company }\end{array}$




\section{Executive Summary}

The Kigali Amendment to the Montreal Protocol on Substances that Deplete the Ozone Layer calls for the phasedown of hydrofluorocarbons (HFCs) with high global warming potential (GWP) that are used in a diverse array of applications, including refrigeration, foam blowing, and air conditioning. ${ }^{1}$ Much attention is focused on the air-conditioning sector, which is projected to grow substantially, especially in developing regions. ${ }^{2-3}$ The ductless mini-split is a common room air-conditioner design in use worldwide, and its adoption is growing in developing regions. Much of this report focuses on the market for rotary compressors, the type of compressor most commonly used in mini-split room air conditioners. The two types of rotary compressors used in mini-splits are fixed-speed and variable-speed. Fixed-speed units have only two modes: off and on. They cycle on when the temperature in the room gets too warm and turn off once the room has cooled sufficiently. This control method is simpler than that of variable-speed compressors, but it is also less efficient. Variable-speed units can operate at more than one speed in order to maintain a steady room temperature, leading to quieter and more efficient operation overall. The tradeoff is that variable-speed units are inverter-driven and require electronic control systems, which can add to manufacturing cost.

Inverter-driven compressors were first developed for room air-conditioner use by Toshiba in the late 1980s. Our analysis of patent filings relating to inverter technology shows that the number of filings per year has risen sharply since then. The rate of patent applications relating to this technology reached an all-time high in 2016. We also find that the design of lubricants for efficient cooling equipment is an important area of research and development in the transition to low-global warming potential (GWP) refrigerants. Lubricant oil formulations developed for use in compressors with earlier generations of HFCs were incompatible with R-32, one of the low-GWP alternative refrigerants. Compatible oils have since been developed and patented for room air-conditioner use.

Before proceeding further into the main report findings, it is worth reviewing the refrigerants and associated terminology that appear throughout this report. The "R-" nomenclature is used when referring to a gas or mixture of gases as a refrigerant. $\mathrm{R}-22$ and $\mathrm{R}-32$ are individual gases: HCFC-22 and HFC-32, respectively. R-410A is a mixture of HFC-32 and HFC-125. The hydrocarbon R-290 is more commonly known as propane outside the cooling sector. The GWP of a greenhouse gas is a measure of the amount of global warming impact associated with the gas relative to carbon dioxide, which is defined as having a GWP of one. On a 100-year timeframe, the GWPs of R-22, R-410A, R-32 and R-290 are 1810, 2088, 675 and 3.3, respectively. ${ }^{4}$

This report covers the major characteristics of the global rotary compressor market. It focuses on opportunities and challenges for adoption of the higher efficiency units. Company-specific compressor production capacity data show that nearly all rotary compressor production is concentrated in Asia, specifically China. The largest compressor manufacturing companies in China include GMCC, Gree, Highly, and Rechi. We find that these four companies, combined, account for over $60 \%$ of current global rotary compressor production capacity; GMCC alone 
accounts for about a quarter of global capacity. Other countries with rotary compressor production capacity as of 2018 include (in descending order of production capacity) Thailand, South Korea, Malaysia, Japan, India, Brazil and the Czech Republic. A compilation of data from company catalogs and websites indicates that rotary compressors using refrigerants with higher GWP, R-22 and R-410A, still account for the majority of models available worldwide. Many companies now offer both fixed-speed and variable-speed compressors. None of the variablespeed models identified in our search of major manufacturers' compressor offerings use R-22 as a refrigerant; the variable-speed units use either R-410A or one of the low-GWP refrigerants: R-32 or R-290. In China, $42 \%$ of the 167 million rotary compressors produced in 2017 were of the variable-speed type; in 2012, only $30 \%$ of the 103 million Chinese-manufactured compressors were variable-speed.

China accounts for the largest share of global rotary compressor trade, with significant flows to air-conditioning manufacturing hubs in Brazil, Europe, India, Japan, South Korea, Thailand, and other regions. However, more than $80 \%$ of the compressors produced in China are not exported; instead, they are used in the domestic manufacturing of air conditioners and are then exported as final products to other regions or sold to consumers within China.

Looking further up the air-conditioner supply chain, we find that manufacturers currently rely on imports from several countries for parts used in the manufacture of both compressors and air conditioners themselves. Companies in countries such as Japan, South Korea, and the United States often supply the electronic components needed for these systems, especially the variable-speed ones. At least one company, Gree, is investing in infrastructure to manufacture electronic control microchips at one of its own plants to reduce reliance on imports. A representative of one manufacturer of air-conditioner parts-including inverter controllers, expansion valves, and heat exchangers - noted the importance of economies of scale in producing these smaller parts; it is usually more economical to have one large facility located in one lower-cost manufacturing region instead of multiple smaller, regionally distributed plants. However, companies with sufficient production capacity across multiple regions can shift production from one region to another to adapt to changing conditions while still meeting demand.

India's growth into a major residential air-conditioning market has precipitated growth in India's domestic room air-conditioner compressor manufacturing. In some cases, companies have migrated compressor production capacity from older or defunct plants in other countries to India (e.g., Tecumseh India bringing in equipment from a former U.S. plant). Conversations with air-conditioning industry contacts in India have indicated that research and development decisions are driven largely by performance of both variable- and fixed-speed units within the intermediate efficiency category of the Government of India's Bureau of Energy Efficiency (BEE) rating system. The costs involved in developing units for this popular "three-star" category are some of the key factors in determining whether to (1) focus overall research and development on further efficiency improvements for fixed-speed models or (2) focus on developing new models with inverter technology. The costs and availability of the necessary electronic control components for inverter models are important factors in that decision. Our industry contacts 
also mentioned a goal of achieving higher efficiency and cooling capacity with smaller compressors in order to keep the costs of the compressors down.

This report also highlights the tight competition in the smaller Middle Eastern market, which relies on imports of both rotary and reciprocating compressors since about half of residential air-conditioning systems sold in this region are window-type. Competition with Southeast Asian compressor suppliers drove U.S. company Bristol Compressors International, one of the major reciprocating compressor exporters to the Middle East, out of business in August 2018. Bristol's compressor manufacturing equipment is now being migrated to Kulthorn Kirby, a compressor manufacturer headquartered in Thailand.

In Brazil, a policy known as the Basic Productive Process has a major impact on compressor and air-conditioner production. The policy provides tax incentives for companies that manufacture products in a remote region of Brazil using a certain percentage of parts sourced in Brazil. Most room air-conditioning unit manufacturers in Brazil source at least some of their compressors from Tecumseh, the only local compressor manufacturer, to meet the Basic Productive Process requirement. Tecumseh provides fixed-speed models that use higher-GWP refrigerant. Due to the remote production location and the resulting high cost of shipping, all production is for the local markets; exports are minimal. The Brazilian market has not grown at the pace of other developing regions, such as India, due to a recent (2014-2016) economic crisis.

China, Indonesia, Thailand, and Vietnam, as well as other countries, have undertaken or are currently undertaking air-conditioning manufacturing line conversion projects under the Multilateral Fund for the Implementation of the Montreal Protocol. The goal of these projects is to mitigate ozone-depleting and high-GWP substances in these developing regions by using low-GWP, next-generation compressors in air-conditioner manufacturing. So far, the projects have exhibited some successes as well as challenges in realizing broader adoption of this technology. The conversion projects in Thailand and Indonesia have highlighted a concern about the availability of higher-capacity R-32 compressors, especially for uses in commercial applications. Availability of compressors using the flammable R-290 refrigerant has also been noted as a concern, although a recent uptick in Chinese production and exports of them may be an early indicator of growing R-290 adoption.

The end goal of this report is to inform the discussion around efforts to transition the global residential air conditioning sector toward more energy-efficient cooling equipment utilizing lower-GWP refrigerants. 


\section{Table of Contents}

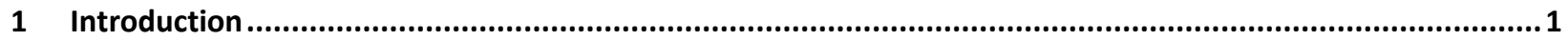

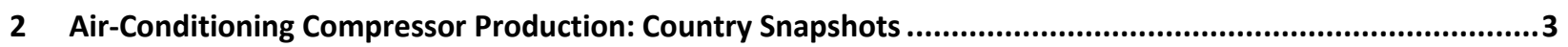

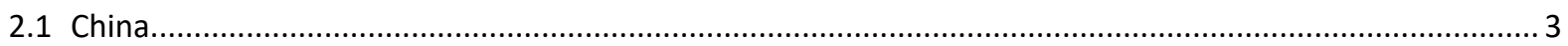

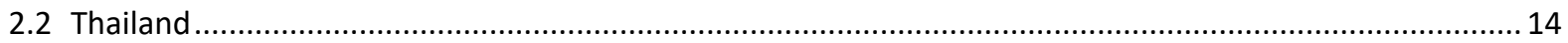

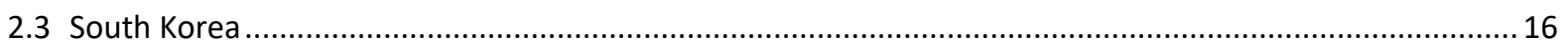

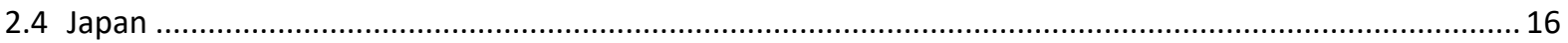

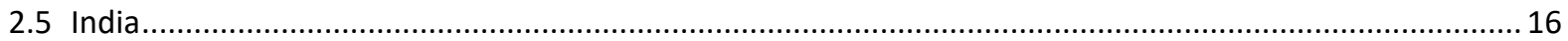

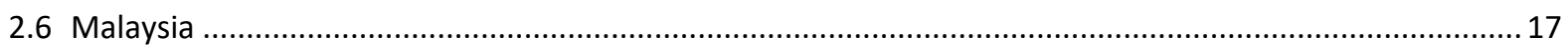

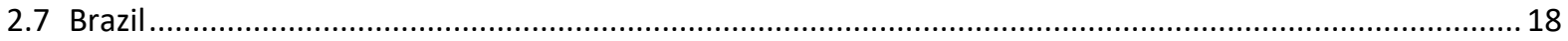

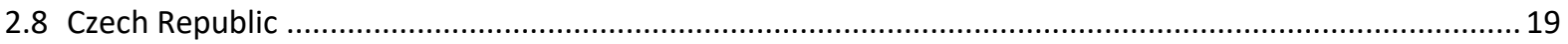

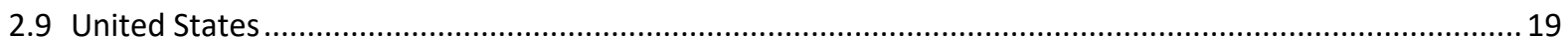

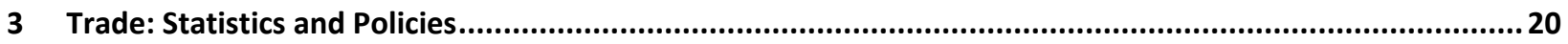

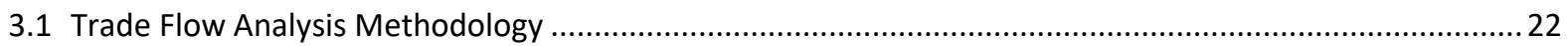

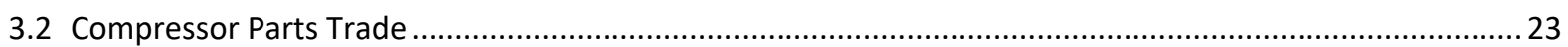

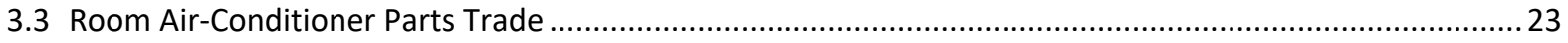

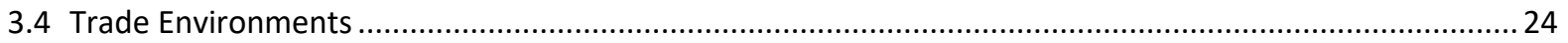

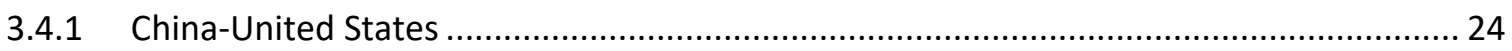

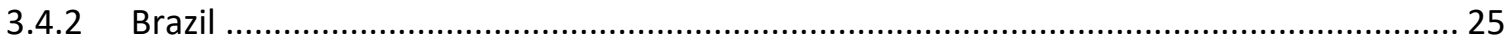

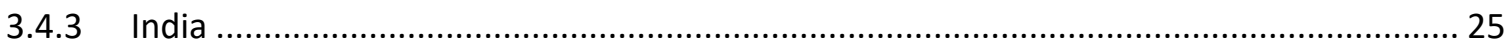

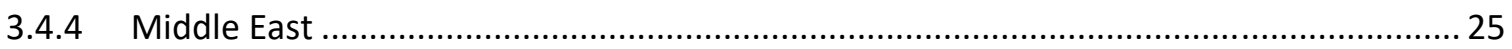

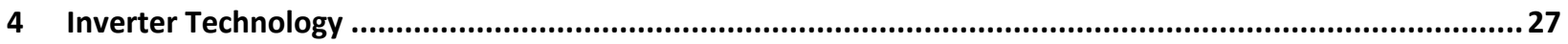

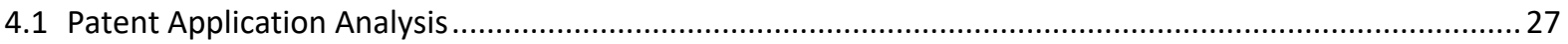

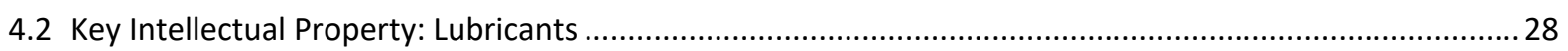

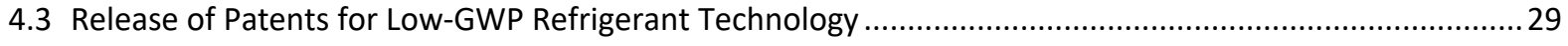

4.4 Reciprocating Compressors and the Refrigerator Market ................................................................29

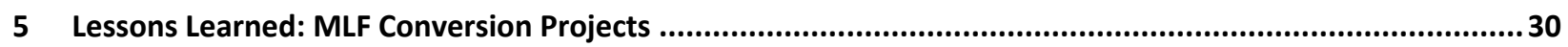

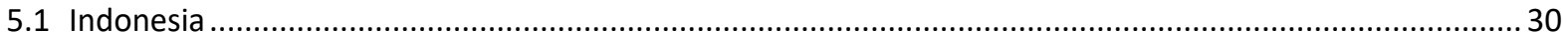

5.2 Thailand

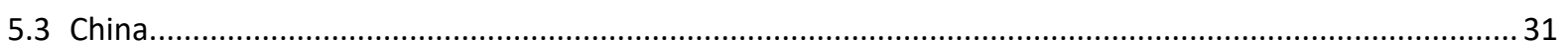

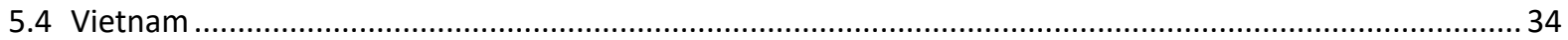

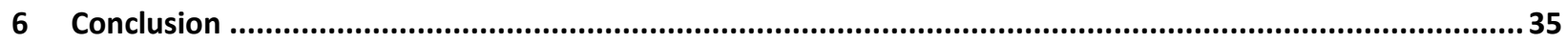

Appendix A. Location and Capacity of Compressor Plants ............................................................................. A-1

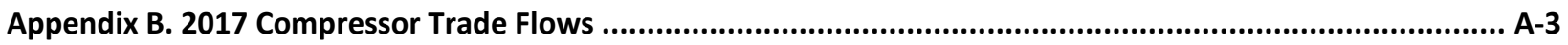




\section{List of Figures}

Figure 1. Sales of Chinese Fixed- and Variable-Speed Rotary Compressors, 2013-2018 ......................................

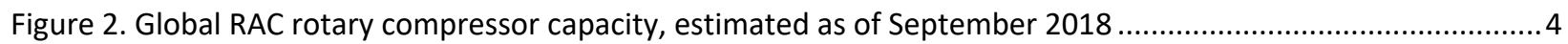

Figure 3. RAC rotary compressor production capacity in Asia, estimated as of September 2018 ...........................

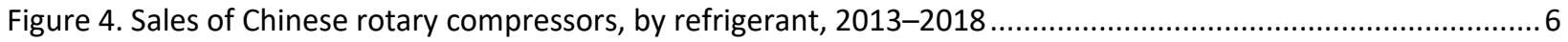

Figure 5. Size distribution of rotary and scroll compressors produced in China in 2017 ....................................

Figure 6. Histogram of the 317 rotary compressor models listed in GMCC's 2018 catalog ................................... 8

Figure 8. Histogram of 199 rotary compressor models listed in Highly's 2018 catalog .......................................10

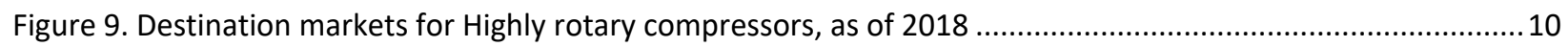

Figure 10. Histogram of 862 rotary compressor models listed on Rechi's website as of September $2018 \ldots \ldots \ldots \ldots . . . .11$

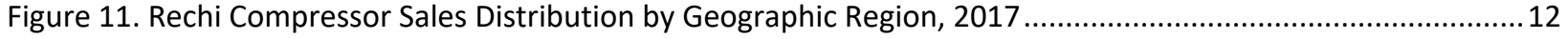

Figure 12. Histogram of 358 rotary compressor models listed in Panasonic's 2018 catalog .................................12

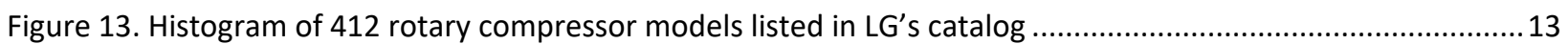

Figure 14. Histogram of 194 rotary compressor models listed in Samsung's 2018 catalog .................................14

Figure 15. Histogram of 309 rotary compressor models listed in Siam Compressor Company's 2018 catalog ..........15

Figure 16. Distribution of BEE Star Ratings for RAC units sold in India.......................................................... 17

Figure 17. Histogram of 128 rotary compressor models listed in Tecumseh's September 2018 catalog ..................18

Figure 18. 2017 Global RAC compressor trade flow, in millions of units.........................................................20

Figure 19. Value and Origin of China's Imports of Compressor Parts, 2001-2017 ...........................................23

Figure 20. Value and Origin of China's Imports of Air Conditioner Parts, 2001-2017 .........................................24

Figure 21. U.S. exports of refrigerator and air conditioner compressors to the Middle East, 1996-2017 ...............26

Figure 23. Distribution of patent applications for RAC inverter inventions, by assignee.....................................28

Figure 24. Chinese Production of Fixed- and Variable-Speed Hermetic Reciprocating Compressors, 2014-2018 .....29

Figure 25. Monthly Chinese production and distribution of R-290 rotary compressors, 2016-2018.....................32

Figure 26. Monthly Chinese production and distribution of R-32 rotary compressors, $2016-2018 \ldots \ldots \ldots \ldots \ldots \ldots . . . . . . . .33$ 


\section{List of Tables}

Table 1. Summary of Estimated 2017 Production Capacity, Imports, Exports, and Trade Balance of RAC Compressors, by Region

Table A-1. Location and Capacity of Compressor Plants, Ordered by Capacity

Table B-1. Compressor Trade Flow Data for 2017 


\section{Introduction}

The Kigali Amendment to the Montreal Protocol on Substances that Deplete the Ozone Layer calls for the phasedown of hydrofluorocarbons (HFCs) with high global warming potential (GWP) that are used in a diverse array of applications, including refrigeration, foam blowing, and air conditioning. ${ }^{1}$ Much attention is focused on the air-conditioning sector, which is projected to grow substantially, especially in developing regions. ${ }^{2-3}$

In most regions of the world outside of the United States, the ductless mini-split is the typical room air-conditioning (RAC) system. Mini-splits are composed of indoor and outdoor units connected by a conduit running on the exterior of the building. Mini-splits are a key target of cooling energy efficiency initiatives because of their growing ubiquity in developing markets. Many consumers in these markets may be unable to afford the more-efficient mini-splits and opt instead for less-expensive units that may use more electricity over a device's lifetime. It is important to note, however, that the correlation between price and efficiency is less well defined at lower efficiency levels, where a wide range of retail prices may be found for room air conditioners of similar cooling capacity and efficiency. At higher price points where efficiency is more heavily marketed as a feature, the positive relationship between retail prices and efficiency is clearer. ${ }^{5}$

The compressor is a key component of any air-conditioning system, from the smallest singleroom mini-split to the largest commercial system. Several types of compressors are used in the heating, ventilation, and air-conditioning industry, and each is designed around one or more specific applications:

- Reciprocating compressors are often used in refrigeration applications, but they can also be found in some air conditioners in harsh climates.

- Scroll compressors are often used in commercial heating, ventilation, and airconditioning systems.

- Screw compressors are used in the largest industrial applications.

- Rotary compressors, most commonly used in residential mini-split systems, generally fall between reciprocating and scroll compressors in the cooling capacity spectrum. Much of this report focuses on the market for rotary compressors.

The two main types of rotary compressor used in air conditioners are fixed-speed and variablespeed. Fixed-speed units have only two modes: off and on. They cycle on when the temperature in the room gets too warm and turn off once the room has cooled sufficiently. The control method involved in fixed-speed operation is simpler than that of variable-speed operation, but it is also less efficient.

Variable-speed units operate at more than one speed, enabling the unit to cycle on and off less frequently and maintain a steadier room temperature. Inverters are a specific case of variablespeed compressors, in which the compressor can operate on a continuum of speeds. Once a room cooled by an inverter unit reaches the desired temperature, the unit reduces power and maintains the desired conditions at a low speed with minimal temperature fluctuation. This leads to overall quieter and more-efficient operation. The tradeoff is that variable-speed units 
are inverter-driven and require electronic control systems, which can add to manufacturing cost.

This report begins with a market overview of air-conditioning compressor production, including coverage of the major manufacturing countries and companies. Next, a trade flow analysis is presented to illustrate how compressors are distributed from the production hubs to consumers all over the world. Intellectual property relating to inverter compressor technology is presented along with some brief background on the history of inverter RAC development. The report concludes with an analysis of lessons learned from projects undertaken with financial assistance from the Multilateral Fund for the Implementation of the Montreal Protocol to convert air-conditioning production lines from ozone-depleting R-22 refrigerant to lowerGWP, non-ozone depleting alternatives.

Lastly, it is worth reviewing the refrigerants and associated terminology that appear throughout this report. The "R-" nomenclature is used when referring to a gas or mixture of gases as a refrigerant. R-22 and R-32 are individual gases: HCFC-22 and HFC-32, respectively. R-410A is a mixture of HFC-32 and HFC-125. The hydrocarbon R-290 is more commonly known as propane outside the cooling sector. The GWP of a greenhouse gas is a measure of the amount of global warming impact associated with the gas relative to carbon dioxide, which is defined as having a GWP of one. On a 100-year timeframe, the GWPs of R-22, R-410A, R-32 and R-290 are 1810, 2088, 675 and 3.3, respectively. ${ }^{4}$ 


\section{Air-Conditioning Compressor Production: Country Snapshots}

This section presents country snapshots for nine countries with air conditioner compressor production capacity as of 2018: China, Thailand, South Korea, Japan, India, Brazil, Malaysia, Czech Republic, and the United States.

\subsection{China}

China is by far the world's largest producer of compressors for room air conditioners, with an estimated annual capacity of approximately 200 million units per year. According to the Chinese industry-run website ChinalOL, approximately $43 \%$ of the RAC compressors sold domestically or exported by China in 2018 were of the variable-speed type, as shown in Figure $1{ }^{6}$ This percentage has increased steadily over the past five years; in 2013, the proportion of variable-speed air-conditioning compressors sold by China was just $33 \%$.

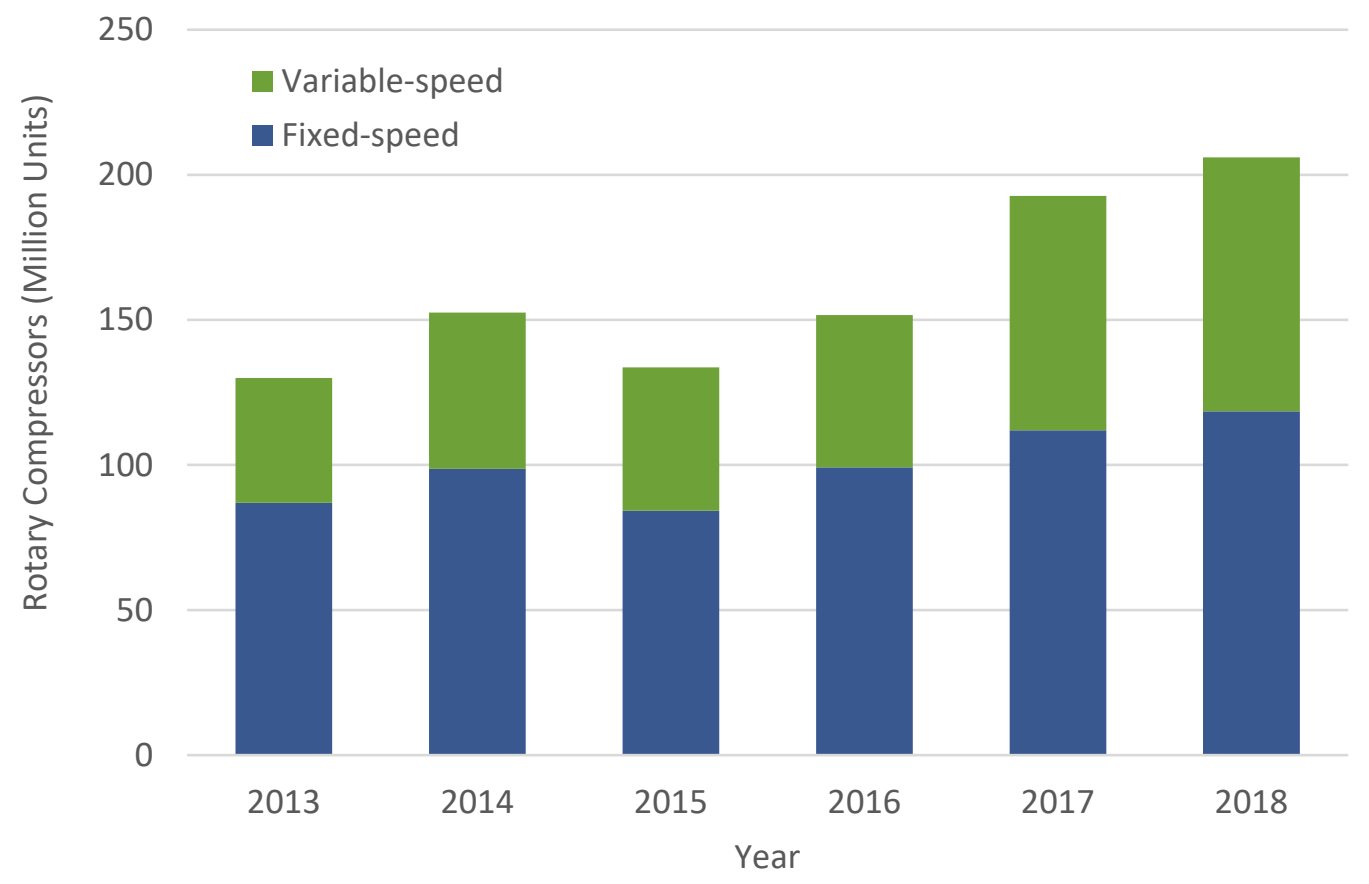

Figure 1. Sales of Chinese Fixed- and Variable-Speed Rotary Compressors, 2013-2018 ${ }^{6}$ 


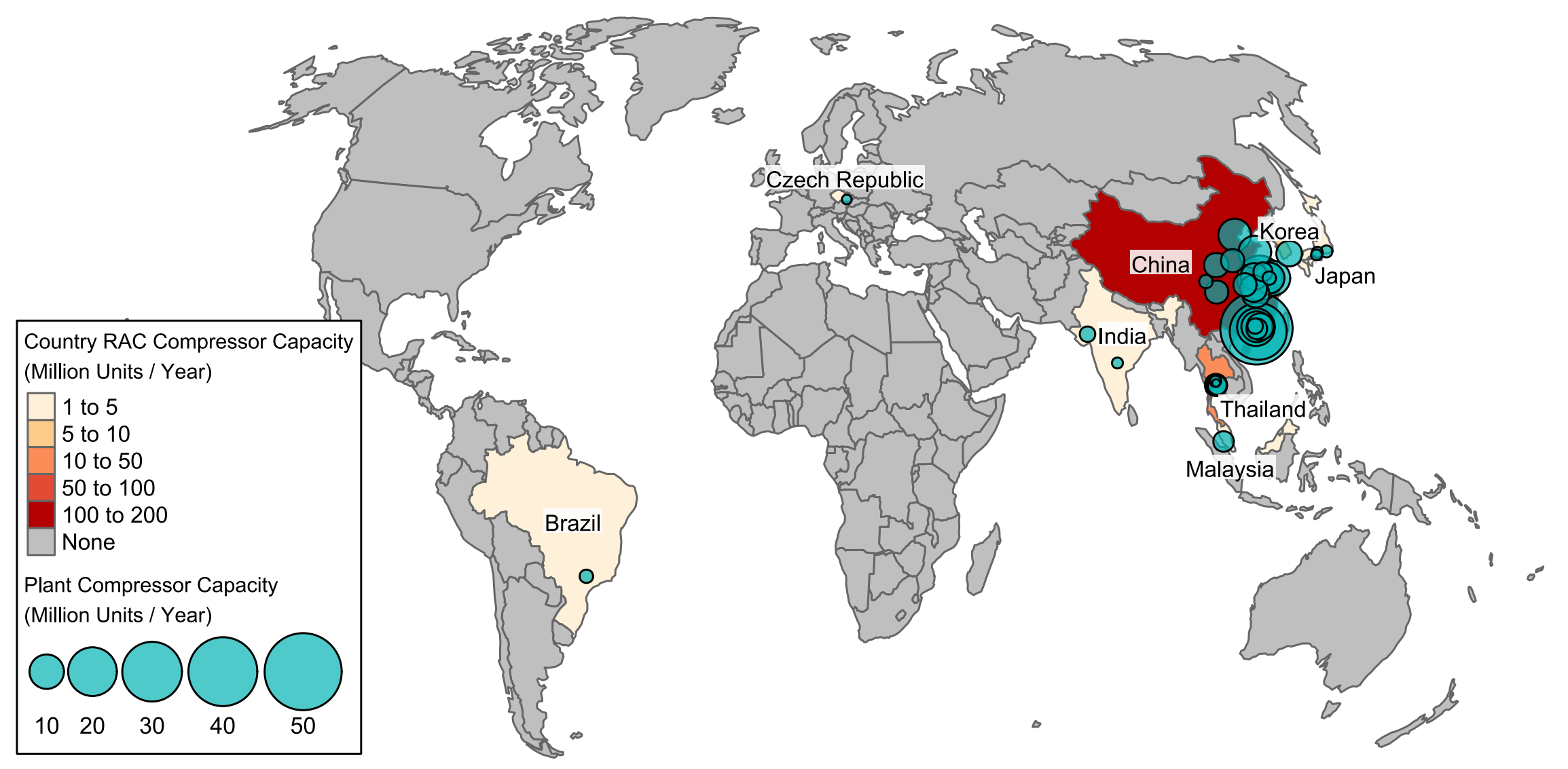

Figure 2. Global RAC rotary compressor capacity, estimated as of September 2018 


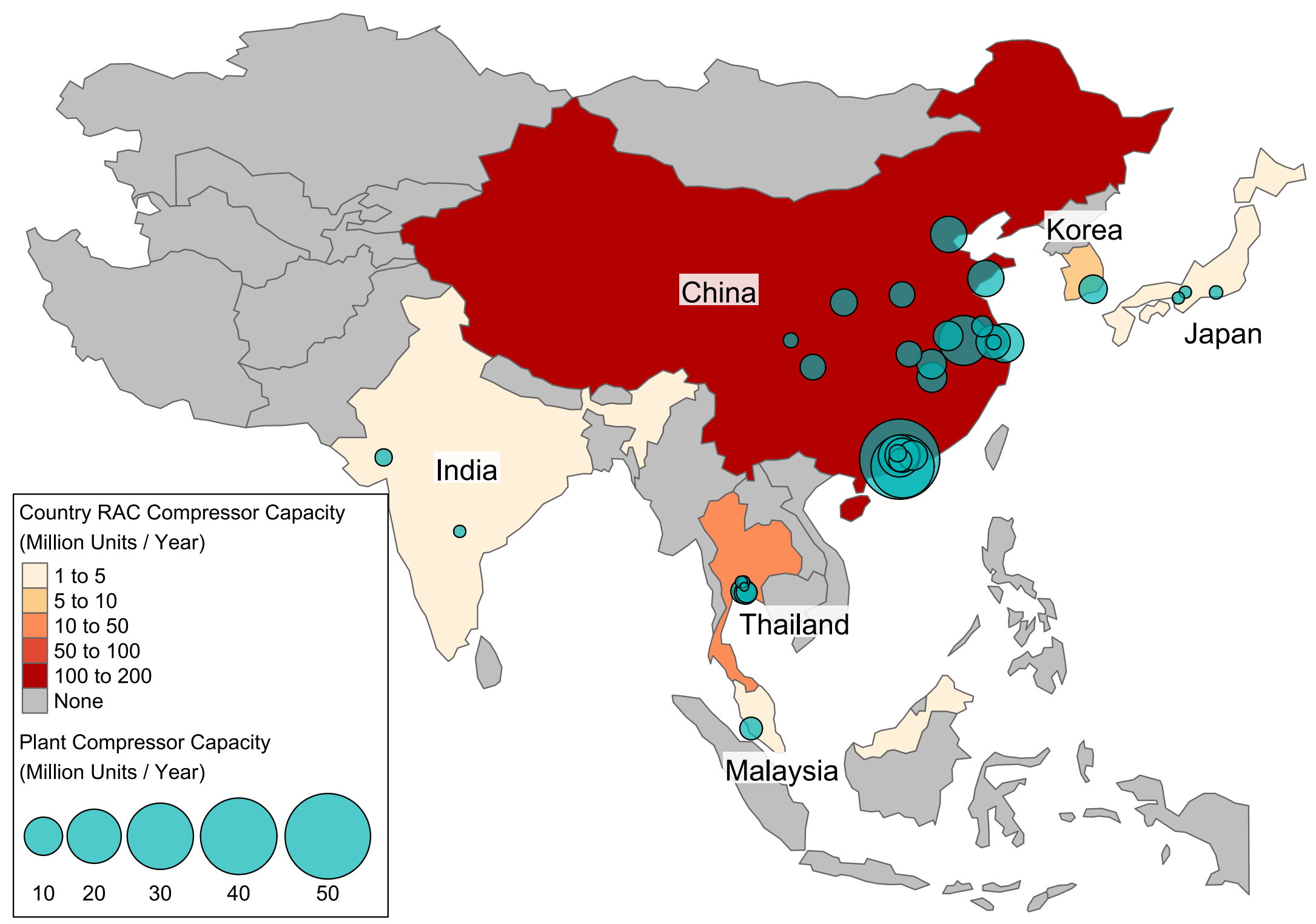

Figure 3. RAC rotary compressor production capacity in Asia, estimated as of September 2018 
All the major compressor factories (i.e., those with greater than 10 million units per year of capacity) are located in China (see Figure 2 and Figure 3). Major air-conditioning compressor manufacturers headquartered in China include Guangdong Meizhi Compressor Company (GMCC), Gree, Shanghai Hitachi Electrical Company, Rechi, Qing'an, Chunlan, Chigo, and Galanz. Other multinational companies with compressor manufacturing operations in China include Panasonic, LG, Mitsubishi, Samsung, and Daikin.

ChinalOL reports that approximately $26 \%$ of the rotary compressors sold by Chinese companies in 2018 were designed to operate with the R-22 refrigerant. ${ }^{6}$ As shown in Figure 4, the quantity of R-22 units has remained constant in recent years, while sales of units using R-410A and R-32 refrigerant has increased. As of 2018, R-410A has become the refrigerant used in the highest proportion of China-produced rotary compressors. R-134a rotary compressors are primarily used in vehicle cooling applications, in contrast to the rest of the rotary compressor market, which is used mainly for room (stationary) air conditioning.

Figure 5 illustrates the distribution of rotary compressor sizes (i.e., cooling capacities), based on the quantities produced in China in the following horsepower ranges: 0-1, 1-3, 3-7, and 7-15. Generally, most residential single-room air conditioners will require air conditioners in the range of 1-3 horsepower. On a unit basis, the scale of rotary compressor production dwarfs that of scroll compressors designed for larger commercial applications. However, for some of these larger cooling applications, higher-capacity rotary compressors are starting to be used in place of the traditional scroll or screw compressors. We spoke with a representative from one Chinese manufacturer who indicated that their company is aiming to expand the market for their higher-capacity rotary compressors into these sectors.

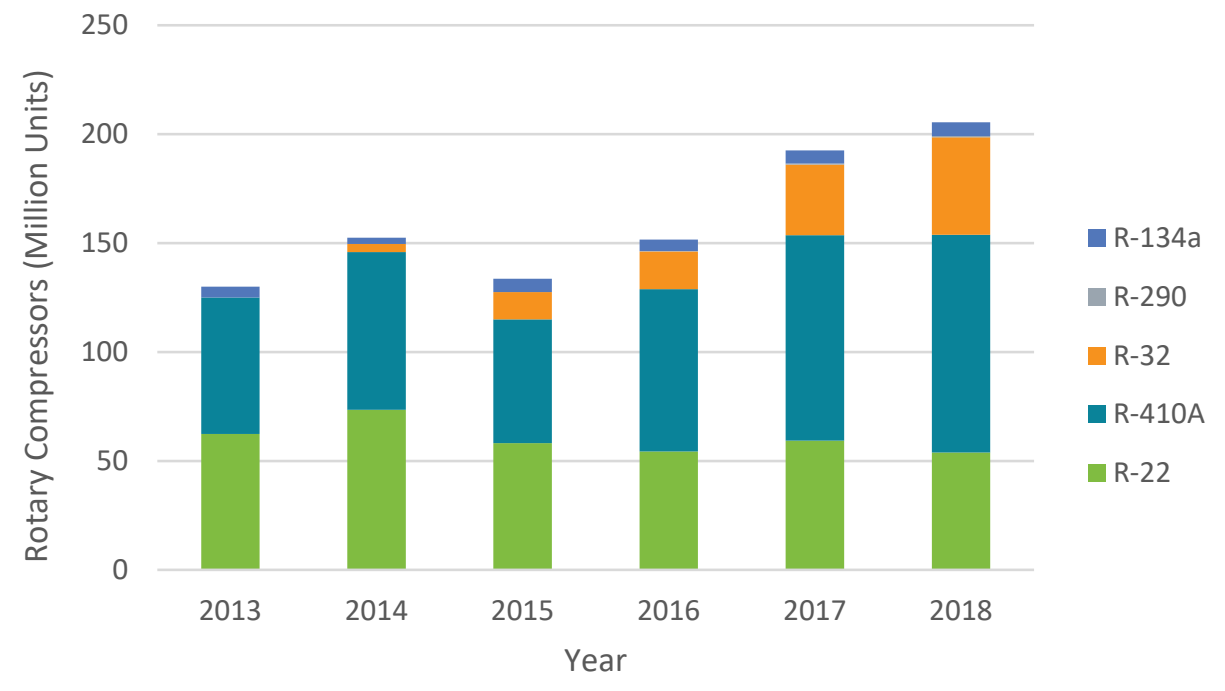

Figure 4. Sales of Chinese rotary compressors, by refrigerant, 2013-2018 ${ }^{6}$ 


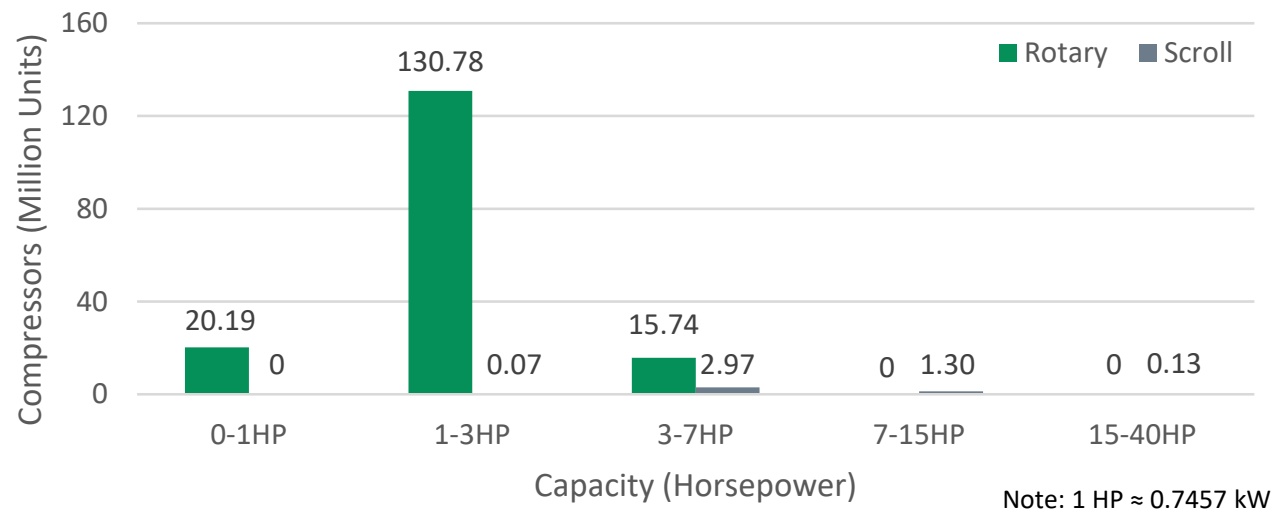

Figure 5. Size distribution of rotary and scroll compressors produced in China in $2017^{6}$

In the following sections, an overview of each major Chinese compressor manufacturing company is provided. These companies include firms based in China and those headquartered outside China that have significant compressor manufacturing capacity within China.

\section{GMCC}

Guangdong Meizhi Compressor Co., Ltd. (GMCC) is a subsidiary of Midea Group, one of the highest-volume producers of room air conditioners in the world. It is unsurprising, then, to find that GMCC produces more air-conditioning compressors than any other company in the world. Headquartered in the Shungfengshan Industrial Zone in Shunde, China, GMCC operates four plants, two of which specialize in air-conditioning compressor manufacturing. On the company website, GMCC claims to have an air-conditioning compressor manufacturing capacity of 65 million units per year as of $2017 .{ }^{7}$ Exact plant-specific capacities are not provided, but we estimate GMCC's main production lines in Shunde to have a combined annual production capacity of 45-50 million compressor units. GMCC's Wuhu plant in the Anhui province has an estimated production capacity of 17 million compressors per year. ${ }^{8}$

GMCC manufactures both fixed-speed and variable-speed compressors, with refrigerant options including R-22 (fixed-speed only), R-410A, R-290, and R-32. A breakdown of GMCC's rotary compressor offerings at a range of capacities is provided in Figure 6. GMCC's inverter compressor models primarily use R-410A as the refrigerant, although some R-32 units are also available. Few inverter units are available at capacities greater than $7 \mathrm{~kW}$. Most of GMCC's fixed-speed compressor models use R-22, although several offerings for R-410A, R-32, and R290 are available, especially in the lower capacity ranges. Detailed specifications for the GMCC rotary compressor lineup can be found in the 2018 GMCC compressor catalog. ${ }^{9}$ 


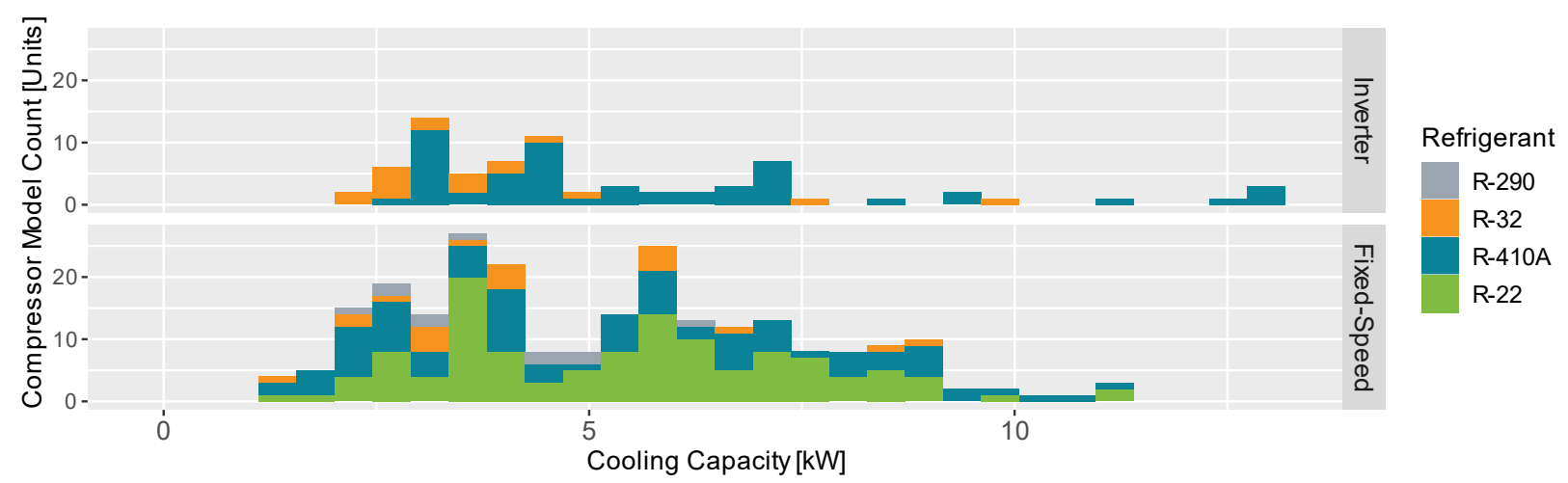

Figure 6. Histogram of the 317 rotary compressor models listed in GMCC's 2018 catalog'

Models are organized by type (fixed-speed versus inverter), compressor capacity in kilowatts (kW), and by refrigerant type (R-22, R-410A, R-32, and R-290).

GMCC sells compressors to domestic RAC manufacturers and also exports compressors, primarily to other Asian countries; in 2015, $89 \%$ of GMCC's exports went to Asian markets. ${ }^{10}$ Major destinations for GMCC compressors outside China include Thailand, India, Indonesia, and the Middle East. GMCC accounts for approximately half of compressor sales in India, including the supply of R-290 compressors to Godrej Appliances, a major RAC manufacturer in India. ${ }^{11}$ GMCC exported 1.1 million compressors to Thailand in 2017, of which $35 \%$ were variable-speed inverter models. ${ }^{12}$

\section{Gree}

Gree Electric Appliances Inc. of Zhuhai, another major manufacturer of residential room air conditioners, has plants to self-supply compressors via its subsidiary, Zhuhai Landa Compressor. The company claims an estimated total annual capacity of 50 million compressors distributed across five Chinese plants. ${ }^{13}$ Gree's largest production base, located in Zhuhai, has an estimated capacity of 27 million units per year. Other plants include those in Heifei (6 million), Zhengzhou (4.5 million), Wuhan (4.5 million), and Chongqing (4.5 million). ${ }^{14}$ As of 2013 , two of the three production lines at the Zhengzhou plant were producing variable-speed compressors, and approximately two-thirds of the Chongqing plant's capacity produces variable-speed units.

Gree manufactures both fixed-speed and variable-speed compressors, with refrigerant options that include R-22 (fixed-speed only), R-410A, R-290, and R-32. A breakdown of Gree's rotary compressor offerings at a range of capacities is provided in Figure 7. Gree's inverter compressor models primarily use R-410A and R-32; only a handful of inverter models are available at the higher capacities. Most of Gree's compressor offerings are the fixed-speed type, and of those, the majority use R-410A. Several offerings of fixed-speed $\mathrm{R}-22$ remain available. 


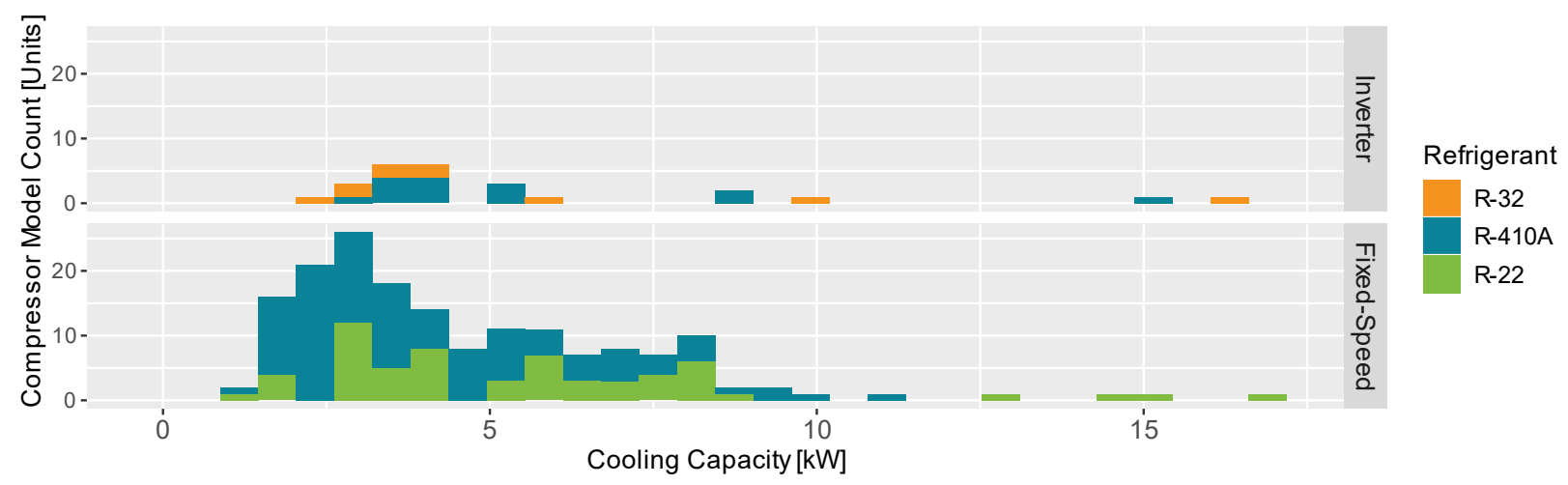

Figure 7. Histogram of the 194 rotary compressor models listed on Gree Landa's website as of September 2018. ${ }^{15}$

Models are organized by type (fixed-speed versus inverter), compressor capacity in kilowatts (kW), and by refrigerant type (R-22, R-410A, and R-32).

In addition to supplying its domestic RAC assembly operations, Gree exports compressors to at least 11 countries, including Brazil, Pakistan, and Thailand. Approximately 400,000 units are exported to Gree's Brazilian manufacturing plant, which primarily manufacturers mini-split models for the local market. Approximately 100,000 compressor units are supplied to Gree's RAC plant in Lahore, Pakistan, which is currently the largest RAC plant in that country. ${ }^{16}$

Microchips are a key part of the electronic control systems needed for inverter-driven compressors. In August 2018, Gree announced plans to establish a chip manufacturing operation. The new subsidiary will be called Zhuhai Zero-Boundary Integrated Circuit Limited and has an initial investment of 1 billion RMB ( $\$ 150$ million), with plans for up to $\$ 50$ billion RMB (\$7.3 billion) total investment. ${ }^{17}$ The company is aiming to self-supply the 4 billion RMB in air-conditioner chips it currently sources from foreign companies by the end of 2019.

\section{Highly}

Shanghai Highly Group Co., Ltd. manufactures air-conditioning compressors via its subsidiary, Shanghai Hitachi Electrical Appliances Co., Ltd, which has an estimated total annual capacity of 20 million rotary compressors distributed across three Chinese plants and one plant in India. The largest plant, located in Shanghai, has a capacity of 10.3 million rotary compressor units per year. Other Chinese plants include those in Nanchang (6.2 million units) and Mianyang (1.5 million units). As of 2018, the Mianyang plant's manufacturing line has focused on inverter compressor production through a 94.50 million RMB (\$14 million) investment approved by the board in late $2017 .{ }^{18}$ of that total, Highly reports that 65.35 million RMB ( $\$ 9.7$ million) went to construction of the new 1.5-million units per year line, which provides a rough estimate of per unit inverter compressor manufacturing line construction costs (ignoring economies of scale) at about $\$ 6.45 /$ unit-year. 


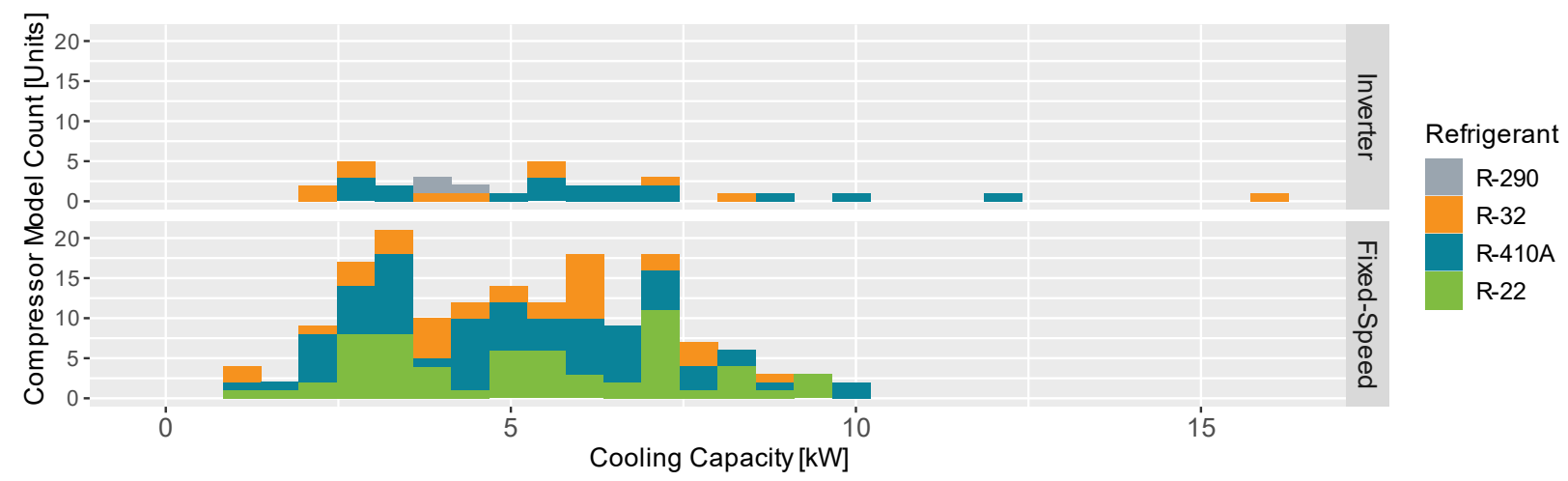

Figure 8. Histogram of 199 rotary compressor models listed in Highly's 2018 catalog $^{19}$

Models are organized by type (fixed-speed versus inverter), compressor capacity in kilowatts (kW), and by refrigerant type (R-22, R-410A, R-32, and R-290).

Highly manufactures both fixed-speed and variable-speed compressors, with refrigerant options including R-22 (fixed-speed only), R-410A, R-290, and R-32. A breakdown of Highly's rotary compressor offerings at a range of capacities is provided in Figure 8. Highly's inverter compressor models primarily use R-410A and R-32, though a few R-290 inverter models are available. Most of Highly's compressor offerings are the fixed-speed type, and of those, most are either R-22 or R-410A units. However, Highly also offers a number of R-32 fixed-speed compressor model sizes.

Highly exports approximately four million compressors per year, with the remaining 16 million being used by domestic RAC manufacturing. Of the four million that are exported, over a third are destined for India and about three-fourths (three million) are exported to Asia overall, as shown in Figure 9. The remaining one million compressors are exported to Europe, the United States, and the Middle East.

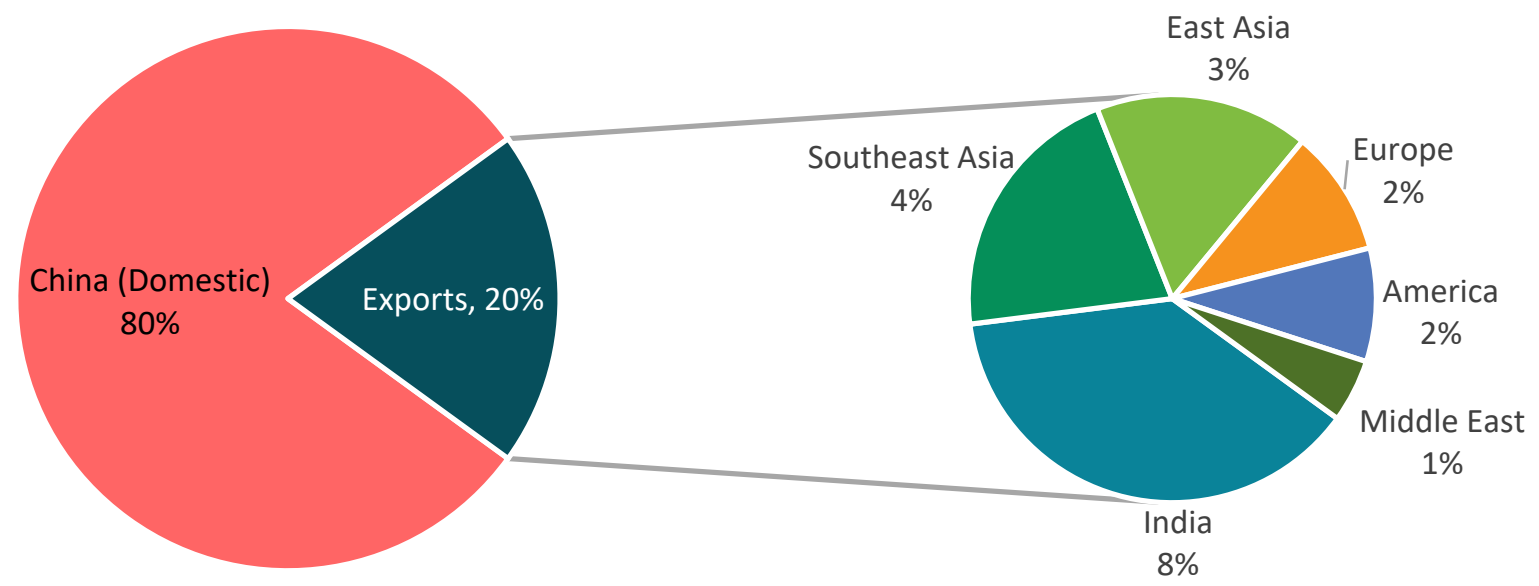

Figure 9. Destination markets for Highly rotary compressors, as of $2018^{20}$ 


\section{Rechi}

Rechi Precision Co., Ltd. manufactures rotary compressors at three factories in China that have an estimated total capacity of 21 million units per year. The largest factory, located in Qingdao, has an annual capacity of 9 million compressors per year with a planned expansion to 12 million units per year in 2019. Rechi's other plants in Jiujiang and Huizhou have annual capacities of six million units each. ${ }^{21}$

Rechi manufactures both fixed-speed and variable-speed compressors, with refrigerant options including R-22 (fixed-speed only), R-410A, and R-32. Rechi's fixed-speed compressor catalog is the largest of any of the major compressor manufacturers examined in this report. The various fixed-speed models, along with Rechi's inverter compressor offerings, are shown as a histogram in Figure 10. Most of Rechi's fixed-speed models are either R-22 or R-410A units, with the latter being limited mostly to capacities of less than $5 \mathrm{~kW}$. Most of the inverter compressor models use R-410A, and the inverter offerings are limited to capacities less than $5 \mathrm{~kW}$. Both fixed-speed and inverter R-32 units are offered.

Compressors destined for inverter and fixed-speed split air-conditioning applications made up a combined $50 \%$ of Rechi's product sales in 2017. ${ }^{21}$ Rechi has a more export-focused compressor business model than many of its Chinese counterparts. When considering all products (including compressors for other non-split air-conditioning and non-air-conditioning applications), customers in Europe and North America each account for roughly a quarter of Rechi sales, as shown in Figure 11. Domestic customers in China make up just a fifth of Rechi's sales.

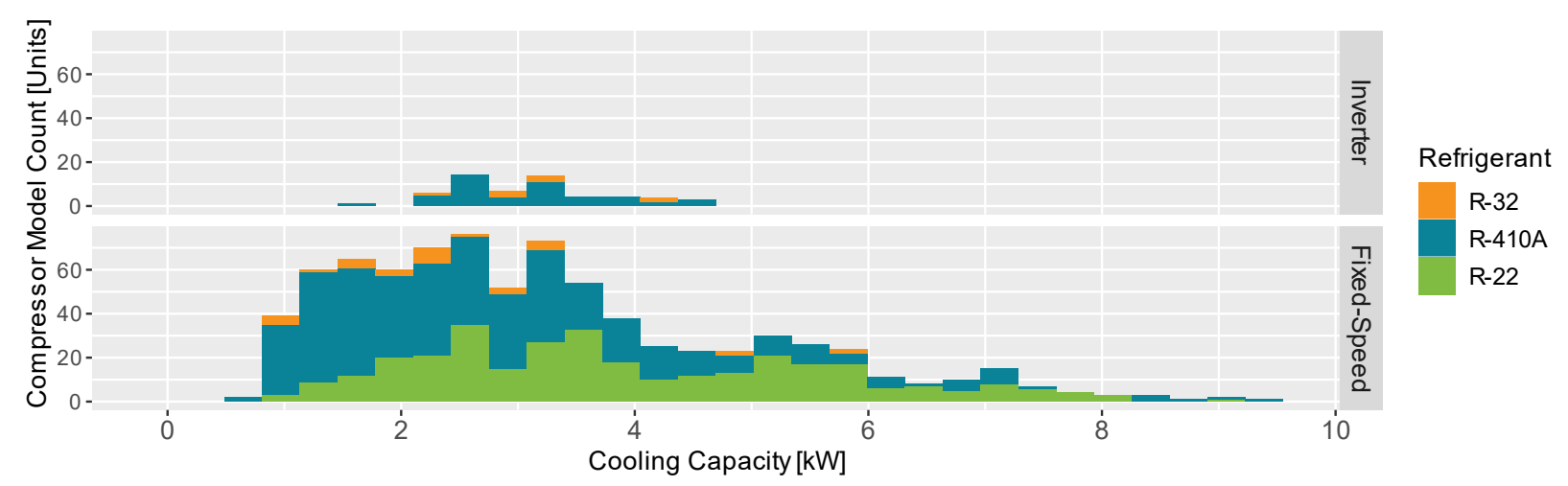

Figure 10. Histogram of 862 rotary compressor models listed on Rechi's website as of September $2018^{22}$

Models are organized by type (fixed-speed versus inverter), compressor capacity in kilowatts (kW), and by refrigerant type (R-22, R-410A, and R-32). 


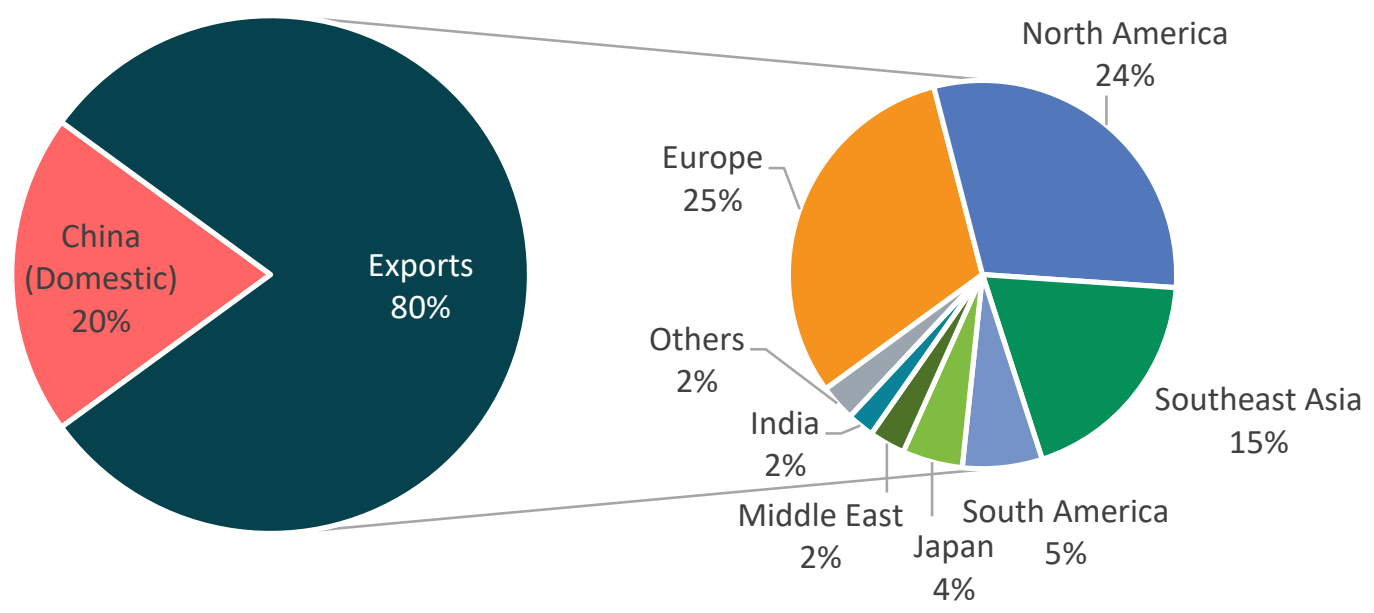

Figure 11. Rechi Compressor Sales Distribution by Geographic Region, $2017^{21}$

\section{Panasonic}

Panasonic, a Japanese company, produces air-conditioning compressors at its Chinese subsidiary Panasonic Wanbao (Guangzhou) Compressor Co., Ltd. plant. It has a capacity of 12 million compressors per year. Panasonic also has a smaller-capacity compressor plant in Shah Alam, Malaysia; for details on that site, see Section 2.6.

Over $90 \%$ of the compressors produced by Panasonic are of the variable-speed inverter type. ${ }^{12}$ This high percentage is indicative of a significant shift in Panasonic's major product lines over the past decade; in 2009, inverter models accounted for just $30 \%$ of Panasonic's production. ${ }^{23}$ Fifty to sixty percent of Panasonic's rotary compressors are sold in the domestic Chinese market, and the remainder are exported..$^{12}$ As shown in Figure 12, most of Panasonic's fixedspeed compressors and all the company's inverter compressors are designed for either R-410A or R-32 refrigerant.

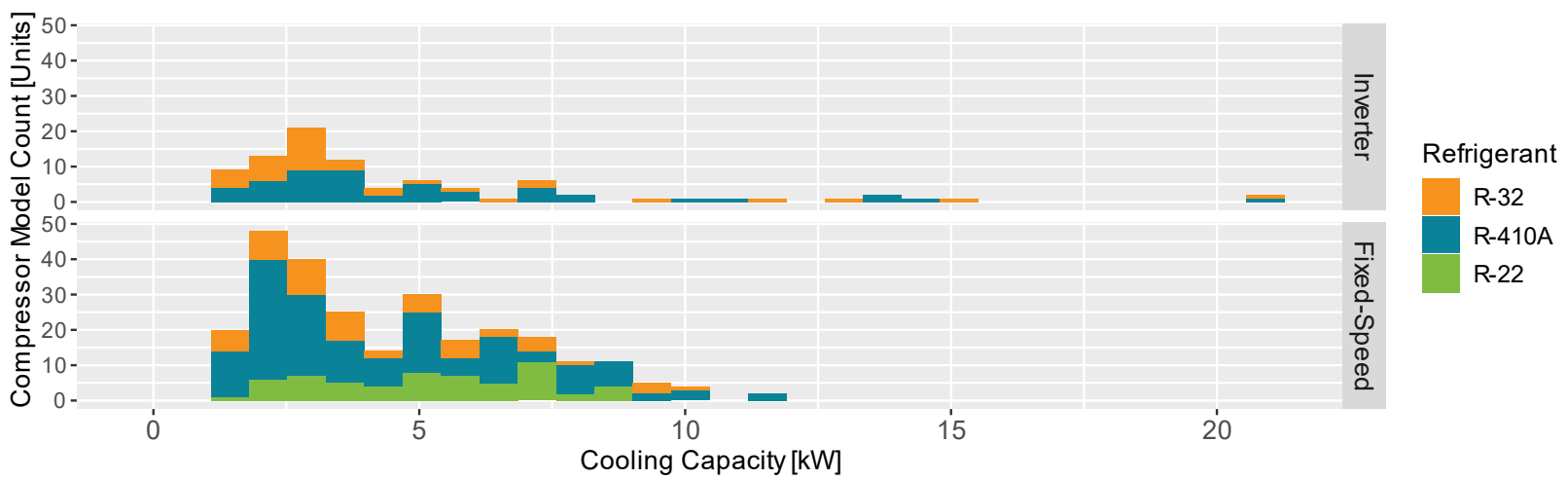

Figure 12. Histogram of 358 rotary compressor models listed in Panasonic's 2018 catalog 24

Models are organized by type (fixed-speed versus inverter), compressor capacity in kilowatts (kW), and by refrigerant type (R-22, R-410A, and R-32). 


\section{LG}

LG produces compressors at a factory in Tianjin, China, which had an annual capacity of nine million units in $2010 .{ }^{25}$ LG also has smaller plants in Thailand and South Korea; for details on those plants, see Sections 2.2 and 2.3, respectively.

As shown in Figure 13, most of LG's fixed-speed units use R-22 or R-410A refrigerant, although some R-32 units are also available. The company also produces R-410A and R-32 inverter units, including some higher-capacity R-410A and R-32 inverter units.

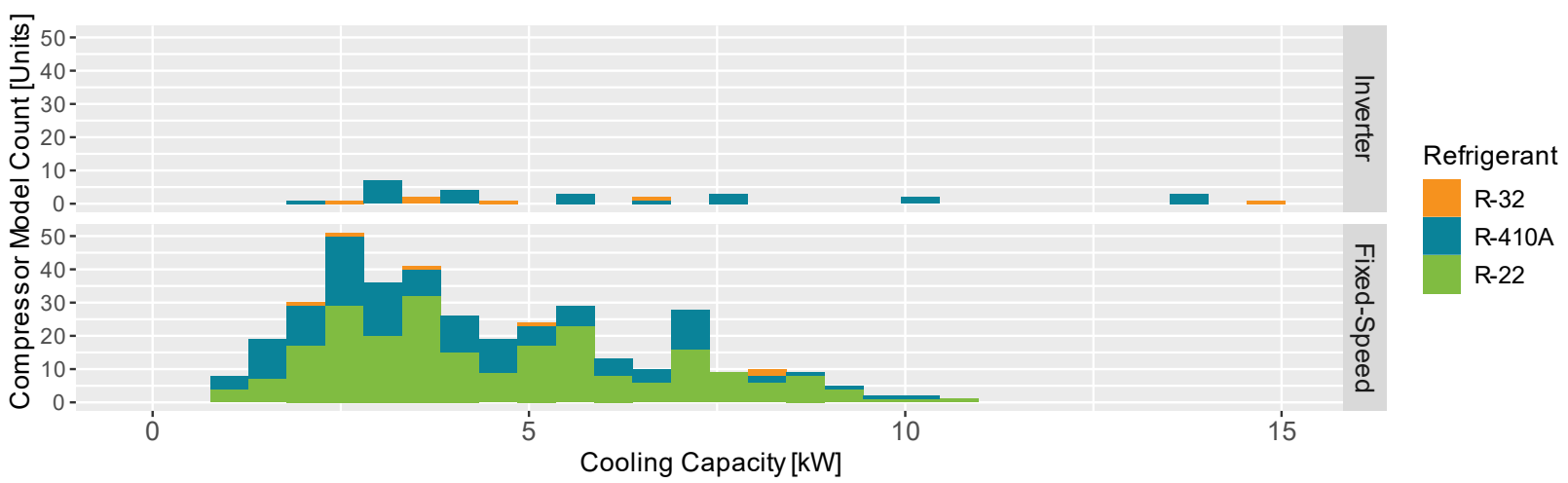

Figure 13. Histogram of $\mathbf{4 1 2}$ rotary compressor models listed in LG's catalog ${ }^{26}$

Models are organized by type (fixed-speed versus inverter), compressor capacity in kilowatts $(\mathrm{kW})$, and by refrigerant type (R-22, R-410A, and R-32).

\section{Mitsubishi}

Mitsubishi, a Japanese company, produces most of its air-conditioning compressors at its Chinese subsidiary Mitsubishi Electric Guangzhou Compressor Company, Ltd. plant. ${ }^{27}$ It has a capacity of eight million compressors per year. Mitsubishi also has smaller-capacity compressor plants in Thailand and Japan; for details on those sites, see the respective country sections (2.2 and 2.4). Section 2.2 includes a histogram of Mitsubishi subsidiary Siam Compressor's compressor model offerings.

\section{Samsung}

Samsung, a Korean company, moved its compressor production from South Korea to China in 2006. Samsung's plant in Suzhou, China, now has the capacity to produce eight million compressor units per year. ${ }^{28}$

As shown in Figure 14, all of Samsung's fixed-speed units use R-22 or R-410A refrigerant. The company also produces some R-410A and R-32 inverter units, including some higher-capacity R-410A units. 


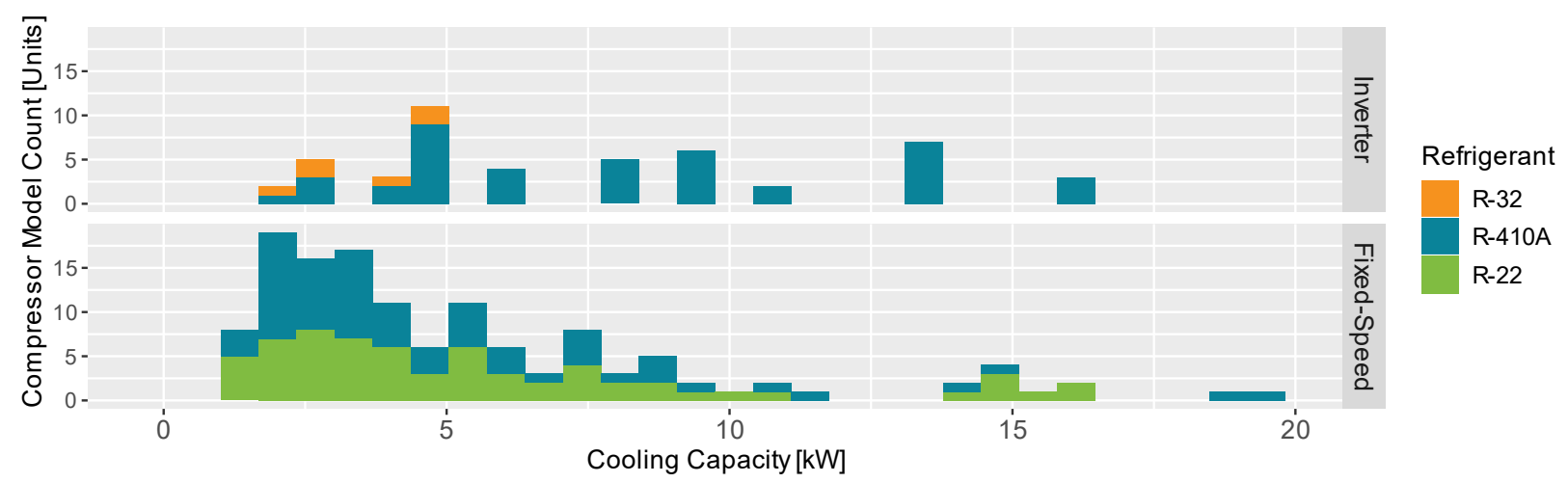

Figure 14. Histogram of 194 rotary compressor models listed in Samsung's 2018 catalog ${ }^{29}$

Models are organized by type (fixed-speed versus inverter), compressor capacity in kilowatts (kW), and by refrigerant type (R-22, R-410A, and R-32).

\section{Other Companies}

Other companies with air-conditioning compressor manufacturing plants in China include AVIC Sanyo (7 million units/year), ${ }^{30}$ Qing'an (5 million units/year), ${ }^{31}$ Galanz (3.6 million units/year), ${ }^{32}$ Chunlan (3 million units/year), ${ }^{33}$ Chigo ( 2 million units/year), ${ }^{34,35}$ and Daikin (1.5 million units/year). ${ }^{36}$ Galanz, Chigo, and Daikin produce compressors solely for internal use in RAC unit manufacturing operations, so detailed data are not publicly available on this subset of compressors. Up-to-date compressor specification data could not be located for AVIC Sanyo and Qing'an.

\subsection{Thailand}

After China, Thailand has the second-highest capacity for rotary compressors, which are primarily supplied to the local air-conditioning unit manufacturing industry. Daikin, Siam (Mitsubishi subsidiary), Kulthorn Kirby, and TCFG (a Toshiba and Fujitsu joint venture) are all companies with significant rotary compressor capacity in Thailand. Production is focused in southern Thailand around the cities of Rayong and Bangkok. Aggregate capacity for the country is around 12 million rotary compressor units per year.

\section{Daikin}

Daikin Compressor Industries and Daikin Industries Thailand are two Daikin subsidiaries that supplement Daikin's fixed-speed compressor supply from Chinese companies such as Rechi. ${ }^{12}$ Daikin Compressor Industries, located in Rayong, has an annual production capacity of about 3.5 million units. ${ }^{37}$ Daikin Industries Thailand, located in Chonburi, has an estimated capacity of 500,000 units per year. ${ }^{38}$ These plants exclusively supply compressors to downstream Daikin RAC applications, so few details about the compressors themselves are publicly available. As of 2015, Daikin has operated production lines for R-32 inverter air conditioners in Thailand. ${ }^{39}$

\section{Mitsubishi}

The Siam Compressor Company factory in Chonburi, Thailand is now a subsidiary of Mitsubishi Electric, and it manufactures approximately four million compressors per year. ${ }^{40}$ This factory produces both fixed- and variable-speed compressors using refrigerants R-410A and R-32. As of 2010, about 75\% of Siam Compressor's production was exported. ${ }^{41}$ 
As shown in Figure 15, most of Mitsubishi's fixed-speed units use R-22 or R-410A refrigerant; some R-32 units are also available. The company also produces some inverter units for use with $\mathrm{R}-410 \mathrm{~A}$ and $\mathrm{R}-32$.

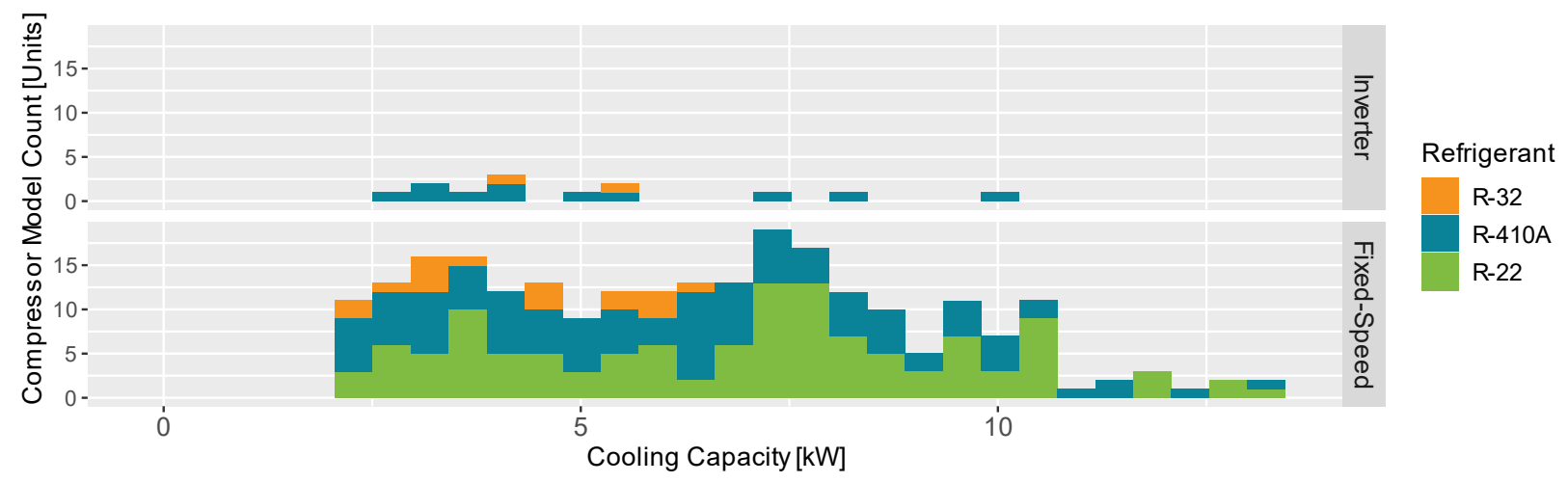

Figure 15. Histogram of 309 rotary compressor models listed in Siam Compressor Company's 2018 catalog $^{42}$

Models are organized by type (fixed-speed versus inverter), compressor capacity in kilowatts (kW), and by refrigerant type (R-22, R-410A, and R-32).

\section{Kulthorn Kirby}

Kulthorn Kirby produces approximately one million air-conditioner compressors annually at its plant in Bangkok, Thailand. ${ }^{43}$ These compressors are of the hermetic reciprocating type designed for harsh climates, and Kulthorn exports them to the Middle East. In November 2018, it was announced that Kulthorn would acquire U.S. manufacturer Bristol Compressor's compressor manufacturing assets. ${ }^{44}$ The equipment will be moved from the former Bristol plant in Virginia to Kulthorn's plant in Thailand, where it will be used to continue producing compressors under the Bristol brand name.

\section{TCFG}

TCFG is a joint venture between Toshiba Carrier and the manufacturing subsidiary of Fujitsu General, FGA. The plant set up through this joint venture has an annual production capacity of 2.5 million units. ${ }^{45}$ Detailed specifications of the compressors manufactured by TCFG are not publicly available because they are primarily supplied internally to Toshiba Carrier and Fujitsu.

\section{THACOM}

Thai Compressor Manufacturing Co. (THACOM), a subsidiary of Mitsubishi Heavy Industries, produces rotary compressors in Chachoengsao, Thailand. The plant has an annual capacity of one million units per year and produces both inverter and fixed-speed models using the R-32 and $\mathrm{R}-410 \mathrm{~A}$ refrigerants. ${ }^{12}$

\section{LG}

LG Corporation produces rotary compressors at a plant in Rayong, Thailand, which has an estimated capacity of three million units per year, as of $2010 .{ }^{25}$ Refer back to Figure 13 for a breakdown of compressor models offered by LG. 


\subsection{South Korea}

As of 2017, LG operates the only major rotary compressor manufacturing operation in South Korea. The plant, located in Changwon, was estimated in 2010 to have a capacity of 5.5 million units, which includes a smaller amount of scroll compressor production. ${ }^{25}$ Samsung had a seven-million unit/year rotary compressor plant operating in Suwon, South Korea up until 2006, when all production was moved to Samsung's factory in Suzhou, China. ${ }^{28}$ South Korea also exports parts for both RAC compressors and the RAC units themselves (see Figure 19 and Figure 20).

\subsection{Japan}

Japan was once a major production hub for air-conditioner compressors, but by the early 2000s, China was starting to overtake Japan as the leading rotary compressor producer. This was primarily due to Japanese companies forming joint ventures with Chinese producers to combine Japanese compressor technology and expertise with the improved economics of lower-cost, higher-volume Chinese manufacturing. Total rotary compressor production in Japan peaked at about 16 million units per year in 1996 and then declined to 8.8 million in 2001 and 6 million units in 2005. ${ }^{38,46}$ The latest figures compiled in Japan Air Conditioning Heating and Refrigeration News (JARN) from Japan's Ministry of Economy, Trade and Industry (METI) and the Japan Refrigeration and Air Conditioning Industry Association (JRAIA) show this trend has continued to the present day, with combined production of compressors for both refrigeration and air-conditioning applications totaling just 4.1 million units in $2017 .{ }^{47}$ Nevertheless, Japan continues to play a key role in the RAC supply chain by supplying air-conditioning components, including lubricants (see Figure 19 and Figure 20 as well as Section 4.2).

\section{Daikin}

Daikin operates two compressor plants in Japan: the Shiga plant is located in Shiga and the Rinkai plant is located in Sakai. Estimates of production capacity at these plants were unavailable, but their combined capacity is likely not more than a few million rotary compressors per year based on the compressor production figures compiled by JARN ${ }^{47}$.

\section{Mitsubishi Heavy Industries}

The Shizuoka Works air-conditioner factory, operated by Mitsubishi Heavy Industries, has an annual production capacity of 1.2 million room air conditioners ${ }^{48}$, and we estimate production capacity for the constituent rotary compressors to be a similar number of units.

\subsection{India}

With its growing domestic demand for residential air conditioning, India is a newcomer to the rotary compressor manufacturing landscape. The Indian market is seen as a key region for developing higher efficiency inverter technology. Currently, room air conditioning has a low market penetration of 4-5\% (as of 2017) in the country ${ }^{49}$, and less than half of 2018 room air conditioner sales in India were projected to use inverter technology. ${ }^{50}$ India primarily manufactures fixed-speed compressors and relies on imports from China to meet inverter compressor demand. The Government of India's Bureau of Energy Efficiency (BEE) created a 1-5 star labeling system ( 1 indicating the least efficient units, 5 indicating the most efficient). 
As shown in Figure 16, the majority of both fixed-speed and inverter models offered for sale in the Indian market fall into the 3-Star category of efficiency. Fixed-speed and inverter RAC units are very similarly priced in this category. The costs involved in developing units in this 3-Star category represent a key factor in determining whether to focus overall research and development on further efficiency improvements for fixed-speed models or to focus on new units employing inverter technology. The costs and availability of the necessary electronic control components for inverter models are important in that decision. Also, industry contacts mentioned a goal of achieving higher efficiency and cooling capacity with smaller compressors in order to keep the costs of the compressors down.

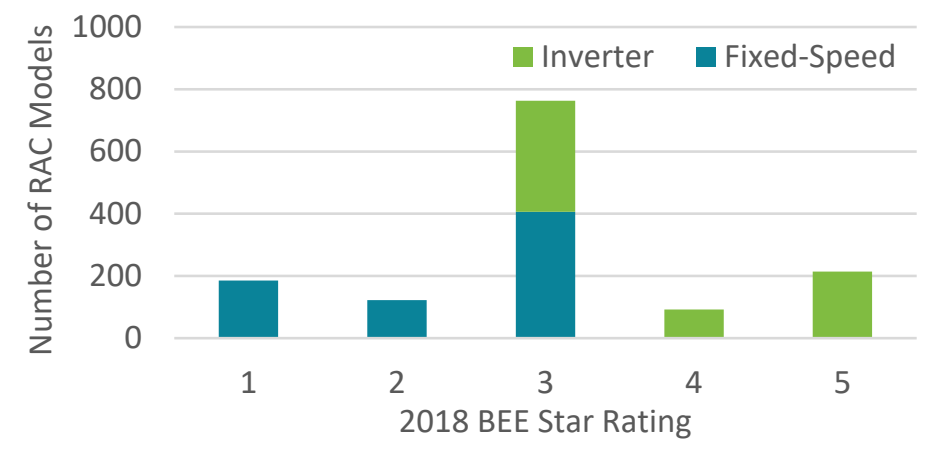

Figure 16. Distribution of BEE Star Ratings for RAC units sold in India ${ }^{51}$

\section{Highly India}

Highly operates a rotary compressor plant in Changodar, India. With a capacity of about two million units per year, this plant currently accounts for approximately $10 \%$ of Highly's total airconditioning compressor capacity. ${ }^{52}$ Highly plans to expand the plant to a capacity of three million units per year in 2019 and to four million unit by $2021 .^{53}$ The plant produces fixed-speed compressors for Highly's " $H$ " and " $L$ " product lines, which include models designed for the especially hot climates found both in India and the Middle East. ${ }^{54}$

\section{Tecumseh India}

Tecumseh Products India, Ltd., a subsidiary of Tecumseh, operates a compressor plant in Hyderabad with an annual rotary compressor production capacity of about one million units. ${ }^{55}$ The plant produces rotary compressors for Tecumseh's "RK" model line of fixed-speed R-22 units. This production line was migrated from Tecumseh's U.S. operations as part of Tecumseh's "best cost country" strategy. ${ }^{56}$ This plant now accounts for $40 \%$ of Tecumseh's current total rotary compressor capacity. Compressors are supplied to local RAC unit manufacturers in India, including Bluestar, Hitachi, LG, and Voltas.

\subsection{Malaysia}

The Panasonic Appliances Air Conditioning Malaysia plant in Shah Alam, Malaysia, has an annual air-conditioning compressor manufacturing capacity of 3.5 million units. ${ }^{57}$ Approximately $70 \%$ of the compressors produced in this plant are used by Panasonic's local airconditioner manufacturing operations, while the remaining $30 \%$ are either sold to other local producers or exported overseas. ${ }^{58}$ 


\subsection{Brazil}

Before the country's economic crisis in 2014, Brazil was seen as a major area of growth in the air-conditioning sector. ${ }^{59-61}$ Many of the largest international RAC manufacturing corporations were incentivized by favorable tax policies to set up manufacturing operations in the country, especially in the duty-free economic zone "Zona Franca" of Manaus.

After economic conditions deteriorated in 2014, however, air-conditioning growth in the country was stifled, and it remains quite small for a country of over $\mathbf{2 0 0}$ million people. The sole rotary compressor manufacturer in the country, Tecumseh do Brazil, has remained in business supplying fixed-speed compressors to the RAC manufacturing operations of international countries, that (with some exceptions) must source a certain percentage of their components from local manufacturers in order to realize the tax benefits of assembling units in Brazil. For a discussion of the policies governing Brazil's air-conditioning market, see Section 3.4.2 as well as the recently published CLASP report. ${ }^{62}$

\section{Tecumseh}

Tecumseh do Brasil, which is headquartered in Sao Carlos and manufactures rotary compressors for the domestic market, has an annual capacity of about 1.9 million rotary units per year. ${ }^{63}$ Though this rotary compressor operation in Brazil accounts for a small fraction of Tecumseh's overall portfolio, the factory is one of the largest employers in Sao Carlos, with a head count of approximately 3,000 workers.

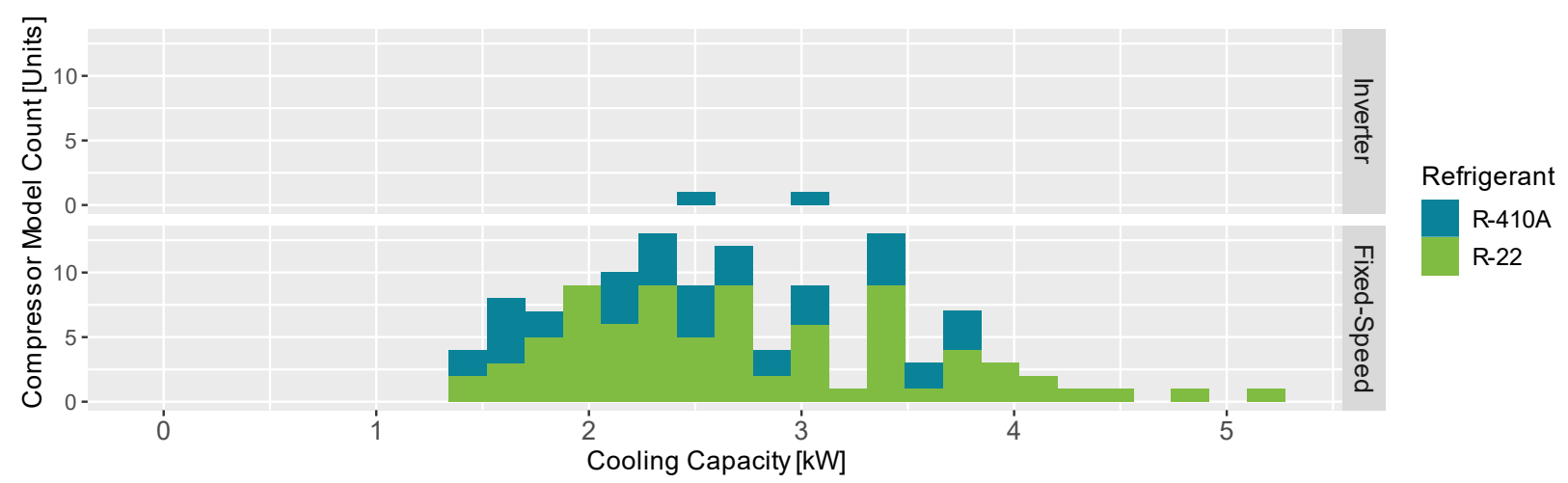

Figure 17. Histogram of 128 rotary compressor models listed in Tecumseh's September 2018 catalog ${ }^{64}$

Models are organized by type (fixed-speed versus inverter), compressor capacity in kilowatts $(\mathrm{kW})$, and by refrigerant type (R-22 and $\mathrm{R}-410 \mathrm{~A})$.

As shown in Figure 17, Tecumseh's compressor model lineup is primarily fixed-speed models using R-22 or R-410A refrigerant. The company also lists two R-410A inverter units in the catalog; however, no inverter units have been produced as of 2018. Tecumseh has indicated it would be willing to expand into additional refrigerants such as R-32 or R-290, as well as selling inverter-based models, if there were sufficient interest from the domestic market. The company has stated that it has a 100 thousand inverter unit capacity line on which it could begin production if it were to start receiving orders for such compressors. ${ }^{62}$ 


\subsection{Czech Republic}

Daikin Device Czech Republic, which is located in Brno, was estimated to produce approximately 790,000 rotary compressors for Daikin air conditioners in $2017 .{ }^{65}$ The Brno plant supplies compressors primarily to Daikin's RAC factory in Pilsen, Czech Republic. ${ }^{66}$

\subsection{United States}

Rotary compressors for air-conditioning applications have not been produced in the United States since Matsushita Compressor Corp. (Panasonic) closed its Mooresville, North Carolina plant in March 2001. ${ }^{38}$ Bristol Compressors International, LLC manufactured reciprocating compressors for refrigerator and air-conditioning applications in Bristol, Virginia, as recently as early 2018. However, the plant shut down in August 2018. Bristol cited weak demand for airconditioning compressors in the Middle East market as the primary reason for the closure. Bristol's compressor manufacturing line equipment is in the process of being transferred to Thai compressor manufacturer Kulthorn Kirby. See Section 3.4.4 for a discussion of the Middle Eastern RAC market. 


\section{Trade: Statistics and Policies}

Figure 18 shows the pattern of global air-conditioning compressor trade flows as of 2017 . The majority of exports originate from China and Thailand, and lesser amounts originate from South Korea, Japan, and India. Chinese compressors are exported worldwide, especially to the RAC unit manufacturing hubs in Thailand, India, and Europe. Thai compressors are primarily exported to China and Japan. It is important to note that the majority of the nearly 200 million air-conditioning compressors produced annually are not exported (and therefore excluded from Figure 18); rather, they are used by RAC manufacturers in the same country where the compressors are produced. Nowhere is this more apparent than in China, where the 28 million exported RAC compressor account for just $17 \%$ of the estimated 167 million rotary compressors produced in the country in 2017 (see Table 1). South Korea, Thailand, and India export approximately $55 \%, 50 \%$, and $20 \%$ of their manufactured air-conditioning compressors respectively.

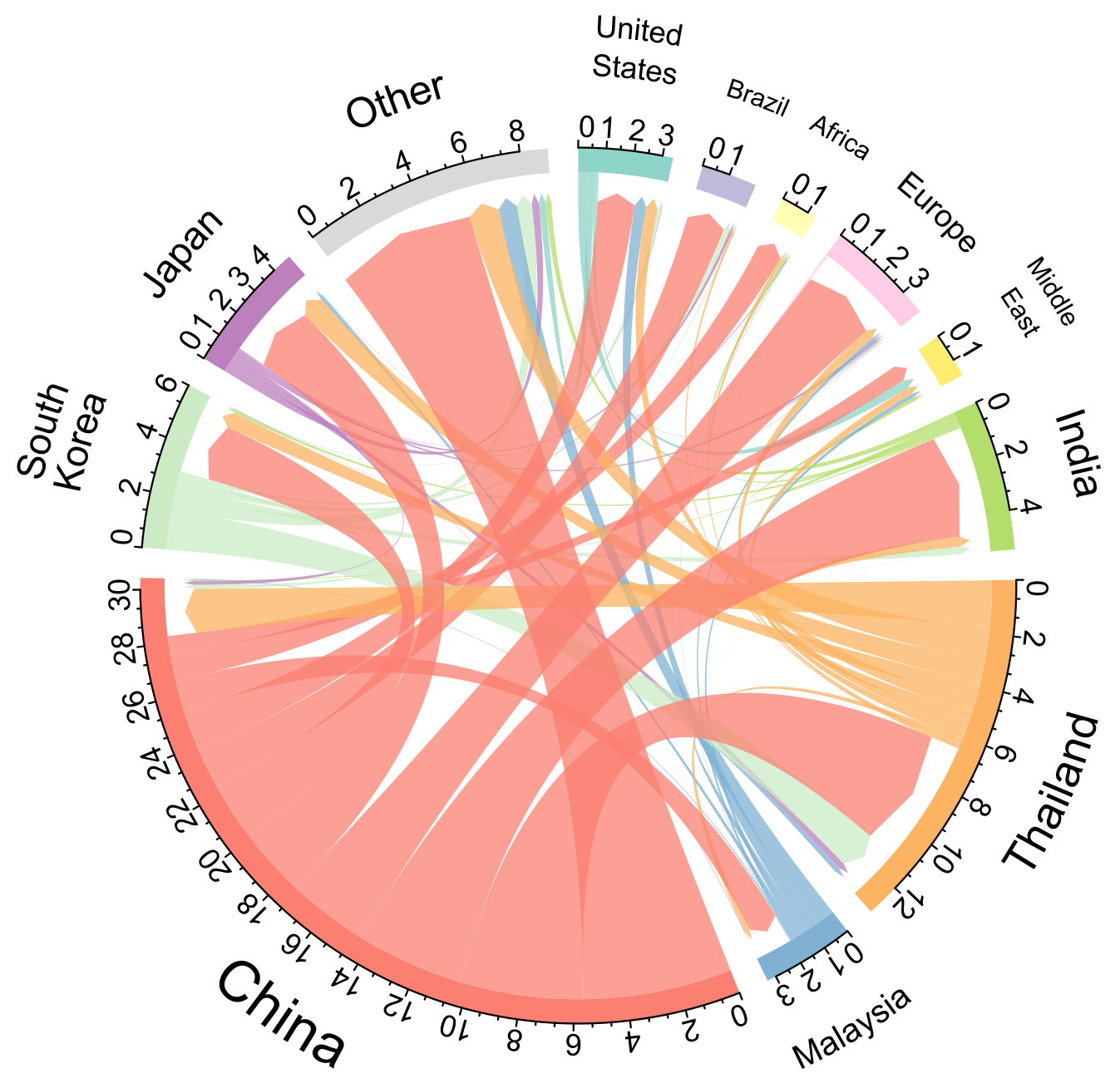

Values in millions of compressor units CEMAC analysis plus data from TradeMap

Figure 18. 2017 Global RAC compressor trade flow, in millions of units

Flow arrow tips indicate direction of trade. Visualized using the $\mathrm{R}$ circlize package. ${ }^{67}$ 
Table 1. Summary of Estimated 2017 Production Capacity, Imports, Exports, and Trade Balance of RAC Compressors, by Region ${ }^{\mathrm{a}}$

\begin{tabular}{r|rccc}
\multicolumn{1}{r}{ Country } & Capacity & Imports & Exports & Trade Balance \\
\hline China & 198.9 & 2.2 & 28.2 & 26.0 \\
Thailand & 13.0 & 6.7 & 6.5 & -0.2 \\
South Korea & 5.5 & 3.0 & 3.0 & - \\
Malaysia & 3.5 & 1.4 & 1.9 & 0.5 \\
Japan & 3.2 & 3.7 & 1.0 & -2.7 \\
India & 3.0 & 4.8 & 0.6 & -4.2 \\
Brazil & 1.9 & 2.0 & - & -2.0 \\
United States & $1.0^{a}$ & 2.6 & 0.8 & -1.8 \\
Europe & 0.8 & 3.7 & $<0.1$ & -3.7 \\
Middle East & - & 1.6 & - & -1.6 \\
Africa & - & 1.3 & - & -1.3 \\
Other & - & 9.0 & - & -9.0 \\
\hline Total & 230.8 & 42.1 & 42.1 & -
\end{tabular}

a Bristol Compressors International, the only U.S. producer of air-conditioning compressors, ceased production as of August 2018.

Data are in millions of compressors.

Source: TradeMap.org and CEMAC analysis

Though China and Thailand account for most of the largest flows, several smaller flows are worth mentioning. The first of these is the flow- of fewer than 300,000 units - from the United States to the Middle East. We assume this flow is primarily reciprocating compressors shipped from Bristol Compressors, a firm that ceased operations in 2018. The Middle East is a smaller compressor market - total imports of compressors were just over one million units in 2017and in an industry governed by economies of scale, Bristol evidently was not realizing sufficient sales volume to compete with compressors imported from China, Thailand, and India. For an equivalent figure developed after 2018, there would be no air-conditioner compressor exports originating from the United States unless another U.S. company begins manufacturing compressors.

Another compressor trade flow, or rather a lack of flow, is that from Brazil. Tecumseh is the only air-conditioning compressor manufacturer in Brazil and does not export air-conditioning compressors. ${ }^{62}$ However, Brazil did export about 10 million compressors to destinations such as Mexico and Italy in 2017 under the broader compressor trade code. Closer inspection of the market revealed that Embraco, a refrigeration company, also has compressor manufacturing operations in Brazil and has refrigerator plants in Mexico, Italy, and elsewhere. Therefore, all of Brazil's generic compressor exports are assumed to be for refrigerator applications and are therefore excluded from this analysis. This underscores the importance of isolating the trade flows of compressors covered within the scope of this analysis (i.e., those for residential air conditioners) from the broader category of compressor trade. For a brief additional note on compressors used in refrigerators, see Section 4.4 of this report. 


\subsection{Trade Flow Analysis Methodology}

Globally, air-conditioning compressors fall under Harmonized System (HS) trade code 8414.30, Compressors Used in Refrigerating Equipment. This category includes compressors for multiple applications (refrigeration and air conditioning), and it includes all sizes of units, from those for small, single-room residential applications with power requirements less than 1 horsepower up to commercial and industrial (scroll- or screw-type) compressors with power requirements that are more than an order of magnitude greater. To remain within the scope of this analysis, it was necessary to restrict the trade flow analysis to compressor units destined for residential airconditioning systems. Conveniently, most of the countries with significant production and/or trade in air-conditioning compressors have implemented detailed trade code schema in which HS trade code 8414.30 is broken down into subcategories. Countries typically disaggregate this trade code by cooling capacity or separate them by application type. For example, the U.S. International Trade Commission's Harmonized Tariff Schedule of the United States separates the HS trade code 8414.30 into nine subcategories: two for larger and smaller screw-type compressors, one for motor vehicle compressors, one for ammonia-based compressors, and five categories for the remaining compressors separated by capacity in horsepower: $<1 / 4,1 / 4-$ $1,1-3,3-10$, and $>10$. The middle three categories within these latter five together account for compressors from $1 / 4$ horsepower to 10 horsepower, and they were assumed to represent all U.S. trade in residential air-conditioning compressors for this analysis. Similar assumptions were made for other countries, all of which have slightly different subcategories under HS trade code 8414.30. Understanding the relative sizes of residential, commercial, and industrial airconditioning compressors, as well as the general sizes of those used for refrigeration and airconditioning applications, is critical when performing such disaggregation of the trade data. In general, refrigeration compressors tend to be smaller than even residential air-conditioning compressors, so separating trade flows by application on the basis of capacity, when such subcategories exist in the trade data, is fairly straightforward. This does not preclude the possibility of a larger refrigeration compressor or a smaller scroll compressor being counted as an air-conditioning unit or air-conditioning compressors at the extremes of the typical capacity range being excluded in this analysis.

China disaggregates HS trade code 8414.30 into several specific categories including one that is most applicable to residential air-conditioning compressors: HS trade code 8414.3013, Compressors for Air Conditioners with Motor Power Greater than 0.4 kW but Not Exceeding $5 \mathrm{~kW}$. This was helpful for this analysis in multiple ways. First, all compressor trade flows to and from China can be reasonably and quickly determined without a lot of additional disaggregation assumptions. Second, Chinese trade flow numbers can be compared to the bilateral equivalents from their trading partner countries, which may not have as precise of an HS 8414.30 subcategorization. In other words, the exports reported by China to a given country should be approximately equal to Chinese imports reported by that country, and a significant discrepancy can indicate where certain less-precise HS 8414.30 subcategories may be over or undercounting compressor trade.

Most countries report compressor trade in at least two units. Monetary value of the trade flow is always reported. In addition, the quantity is also reported, on a mass basis (kilograms) and/or unit basis (number of compressors). For this analysis, the number of units is the preferred metric, when it is available. Compressor values vary widely based on size and performance 
characteristics, and in a trade flow analysis where there is the potential for erroneously counting a more expensive commercial or industrial compressor as a residential unit, accounting on a unit basis mitigates the error associated with this miscategorization. An error of $+/-1$ unit for miscounting a bigger compressor is preferable to the potential value-based error of $+/$ - thousands of U.S. dollars-a much larger compressor unit might be valued several orders of magnitude higher than a residential rotary compressor. Unit-based trade flow analysis can also provide a reasonable basis for inferring the actual number of RAC units produced in each importing region when combined with domestic capacity figures.

In the end, the accuracy of the trade flow analysis is determined by the reliability of the trade data reported by each country, as well as the degree to which trade code subcategorization is available. The inclusion of subcategories for fixed-speed and inverter compressors, which to our knowledge do not exist in any country's trade schema, would be necessary to more closely track the flow of lower- and higher-efficiency air-conditioning compressor units.

\subsection{Compressor Parts Trade}

At the finest resolution currently available, international trade statistics for compressors of both air conditioners and refrigerators/freezers are grouped together. China imported over $\$ 300$ million worth of these compressor parts in 2017 , and $57 \%$ of these imports came from Japan (Figure 19). The United States and South Korea were the source of most of the remaining imports, at \$46 million and \$43 million, respectively. Looking at longer-term trends, it is clear these trade flows have increased significantly since the early 2000s, indicating that China's rising compressor manufacturing capacity has resulted in an increasing reliance on certain key compressor parts from Japanese, Korean, American, and other suppliers.

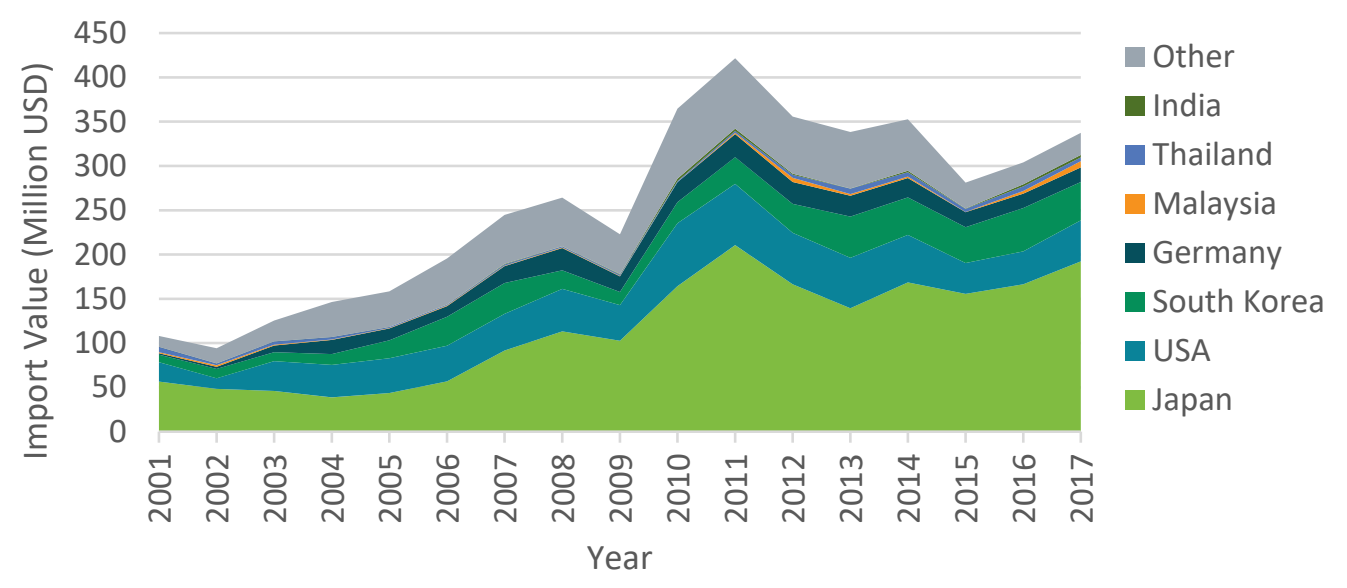

Figure 19. Value and Origin of China's Imports of Compressor Parts, 2001-201768

Annual totals reported under trade code 8414.9019 (parts of compressors for air conditioners, refrigerators, and freezers)

\subsection{Room Air-Conditioner Parts Trade}

Japan accounted for nearly $40 \%$ of the half a billion USD worth of air-conditioning parts imported by Chinese manufacturers in 2017 (Figure 20). China also imported parts from Thailand (\$75 million) and South Korea (\$48 million), along with a smaller but growing quantity 
of parts from the United States (\$47 million). It is unclear which specific products are covered under this category of traded goods; however, the category does include the parts used for external RAC unit housing as well as the more sophisticated electrical components such as inverter controllers.

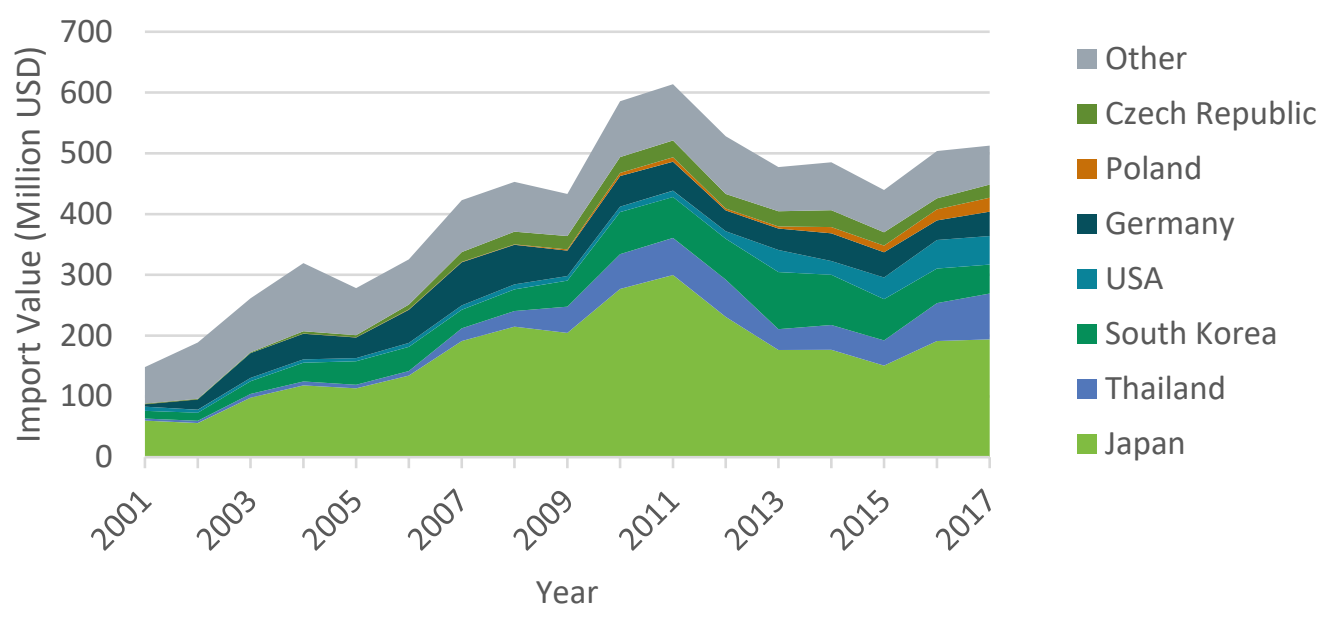

Figure 20. Value and Origin of China's Imports of Air Conditioner Parts, 2001-201768

Annual totals reported under HS trade code 8415.90 (parts of air conditioning machines)

\subsection{Trade Environments}

\subsubsection{China-United States}

The trade balance between the United States and China in the air-conditioning sector is tilted heavily toward Chinese exports. In July 2018, the United States enacted a 25\% tariff on a list of products that, in aggregate, totaled approximately $\$ 34$ billion worth of Chinese imports. ${ }^{69}$ The initial list included air-conditioning compressors but did not include air-conditioning units themselves. In August 2018, China proposed tariffs on U.S. imports, including a proposed 20\%$25 \%$ on air-conditioner parts. These tariffs were later revised down to $5 \%-10 \% .{ }^{70}$ The United States responded by proposing tariffs on an additional set of Chinese products, this time including air-conditioning units. These newest tariffs, which start at $10 \%$ increasing to $25 \%$ in 2019, went into effect in September $2018 .{ }^{71}$ After a delay in the increase to the $25 \%$ rates during continued negotiations, the higher tariff levels were in the process of going into effect as of the completion of this report (May 2019). ${ }^{72}$

On an aggregate value basis, most Chinese imports of parts for air conditioners and for airconditioning compressors actually come from Japan, with a small fraction coming from the United States (see Figure 19 and Figure 20). A representative of one manufacturer of airconditioner parts, including inverter controllers, expansion valves, and heat exchangers, noted the importance of economies of scale in producing these smaller parts-it is usually more economical to have one large facility located in one lower-cost manufacturing region rather than multiple smaller, regionally distributed plants. Companies with sufficient production capacity across multiple regions can shift production from one region to another to adapt to changing conditions while still meeting demand. 


\subsubsection{Brazil}

Air-conditioning compressor production and trade in Brazil centers on a policy known as the Basic Productive Process, which provides tax incentives for companies that manufacture products in Brazil. However, to be eligible for the tax incentives under this policy, companies must source a certain percentage of inputs from local manufacturers. There is an exception to Basic Productive Process for importers of inverter compressors, as these are not produced by Tecumseh, the sole domestic compressor manufacturer. Most RAC unit manufacturers in Brazil source some quantity of compressors from Tecumseh to meet the Basic Productive Process requirement; only three companies do not. Most RAC manufacturing in Brazil is done in the Amazonian city of Manaus due to the free economic zone ("Zona Franca") established there. This remote production location entails increased transportation costs, and companies export hardly any RAC units from Brazil (fewer than 5,000 units were exported in 2017). Essentially, all RAC production is for the small domestic market, which has stagnated due to the Brazilian economic crisis from 2014 to 2016. In July 2018, a minimum efficiency performance standard of 3.02 watts/watt for split air conditioners was announced by the Brazilian government and will go into effect in 2019. For a much more in-depth discussion of the Brazilian air-conditioning compressor market situation, please see the report recently published by CLASP. ${ }^{62}$

\subsubsection{India}

In India, there is a $7.5 \%$ import duty on compressors and a $10 \%$ import duty on air-conditioning units themselves. ${ }^{73}$ Highly's parent company, Shanghai Highly Electrical Company, which imports compressors from China into India and also produces them domestically at the Highly plant in Changodar, has argued that such similarity in duties on imported RAC parts and finished units has not adequately incentivized local RAC production in India. ${ }^{52}$ The company added that its imported products sometimes end up competing with its own domestically produced units due to this duty structure.

\subsubsection{Middle East}

The stagnation of demand for residential air conditioners in the Middle East in recent years is a symptom of broader economic difficulties brought on by lower crude oil prices and political instability. Bristol Compressors International, a U.S. manufacturer of reciprocating compressors, cited this stagnation as the primary reason for closing its Virginia compressor plant and ceasing all operations in 2018. Window-type units account for approximately half of the Middle Eastern residential air-conditioning market. About $10 \%$ of this market is covered by inverter RAC as of 2018. ${ }^{74}$ As shown in Figure 21, exports of compressors (for both refrigeration and airconditioning applications) from the United States to Middle Eastern countries declined from a high of about 1.2 million in 2002 to fewer than 500,000 in 2017. Aside from a brief spike in 2015, perhaps due to Bristol's opening of a sales office in Dubai, the trend in U.S. compressor exports to the Middle East has been unambiguously decreasing since 2010. Exports from the United States to the Middle East are being replaced by a steadily increasing quantity of compressor imports from China and Thailand combined with imports of RAC units themselves from those countries. Bristol had been a supplier for several Saudi appliance manufacturers, including Alessa Industries Company and Zamil Air Conditioners. ${ }^{75,76}$ In November 2018, Bristol's compressor assets and equipment were acquired by Kulthorn Kirby; Bristol's compressor manufacturing equipment will be moved to Kulthorn's Bangkok plant. ${ }^{44}$ 


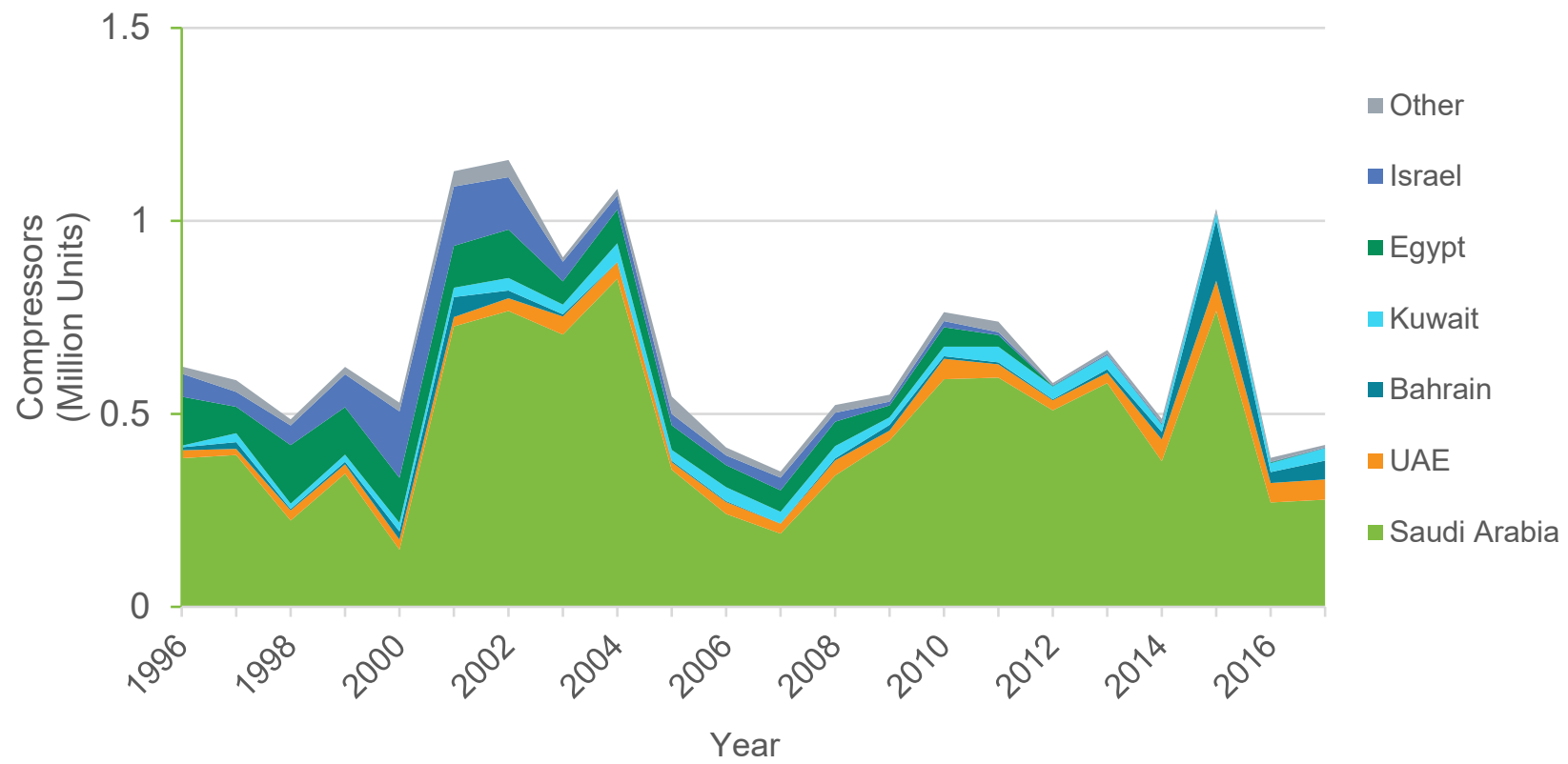

Figure 21. U.S. exports of refrigerator and air conditioner compressors to the Middle East, 1996-2017

Totals are aggregated for U.S. export trade codes $8414.308050,8414.308060$, and 8414.308070 (compressors sized between $1 / 4$ horsepower and 10 horsepower and excluding, screw, ammonia, and motor vehicle type compressors). Data are in millions of compressors. 


\section{Inverter Technology}

\subsection{Patent Application Analysis}

Engineers at Toshiba developed the first inverter air conditioner for household use in Japan in the early 1980s. ${ }^{77}$ A search of the Google Patents database generally reflects this timeline, showing that patent applications for inverter air-conditioning technology were filed by Toshiba starting in 1985 (Figure 22). Toshiba, Daikin, and Samsung were the earliest developers of inverter RAC technology through the 1990s. Since then, several other companies have contributed research and development in this area. As shown in Figure 22, LG began filing patent applications in 2004, and it accounted for a majority of filings through 2009. Mitsubishi filed several applications beginning in 2010. Samsung and Daikin have accounted for most patent applications filed over the past decade. Most recently, Midea appears to be exploring this research space, as it has filed several patent applications starting in 2013.

Figure 23 shows the breakdown in RAC inverter-related patent applications filed by Samsung, Daikin, LG, Hitachi, Mitsubishi, Toshiba, Midea, and others since 1980. These seven companies have combined to account for over three-quarters of the patent applications identified in our database search for inverter control air-conditioning technology. The remaining quarter of patents belong to other entities, including other heating, ventilation, and air-conditioning firms; academic institutions; and individual inventors. Patent counts provide an overview of general trends in research and development, but a major limitation is that they do not measure the importance of individual patents. Not all patent applications are created equally-while a few will go on to become landmark breakthroughs in the industry, many will never even become granted patents.

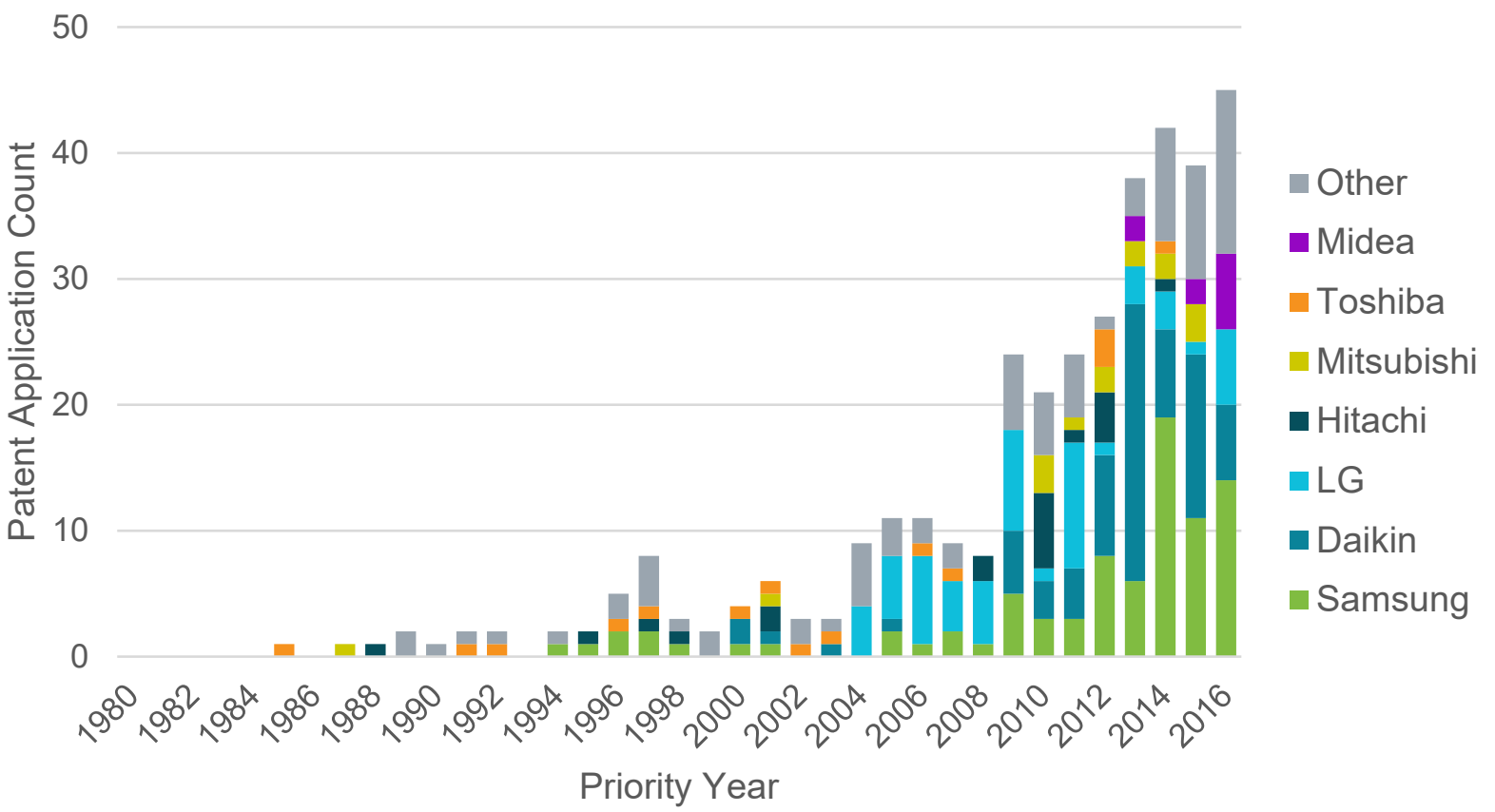

Figure 22. RAC inverter-related patent applications, by year and assignee, 1980-2016 


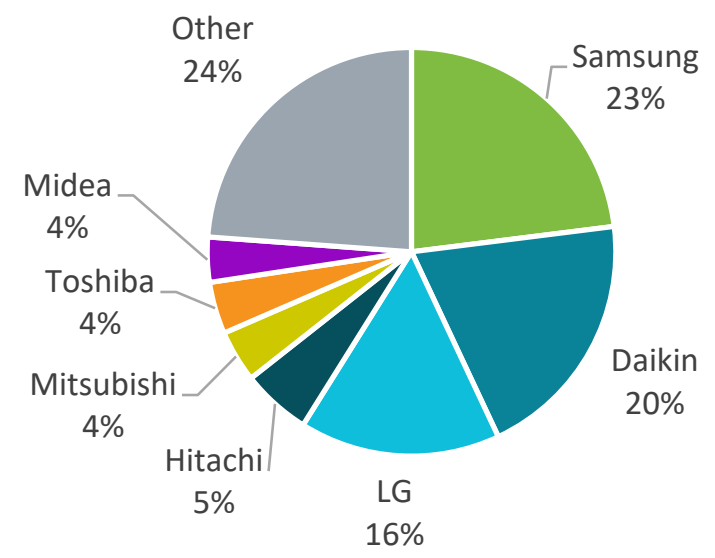

Figure 23. Distribution of patent applications for RAC inverter inventions, by assignee.

The relevant patents were extracted by performing a complex query on the Google Patents database. ${ }^{78}$ Cooperative Patent Classification code F24F, which covers air conditioning, is the first filtering criterion in the search. Of the patents within this classification, those containing each of the terms "inverter", "rotary", "control", and "air conditioner", or variants thereof, were selected. To narrow the search to those patents pertaining to RAC, terms relating to "automobile" were excluded. A total of 365 patent applications were identified.

The Google Patents database mitigates double-counting by grouping patent families, which are essentially the same invention filed in more than one of the major global patent offices. To date, the Google Patents database contains patents from the United States, Europe, Japan, China, and South Korea. The patent application counts presented in this report therefore do not include those filed in countries outside of the Google Patents scope (e.g., those in India's inPASS database ${ }^{79}$ ).

\subsection{Key Intellectual Property: Lubricants}

One key aspect of inverter compressor manufacturing is the selection of lubricants and oils to use within the compressor. Lubricant manufacturers have developed formulations using specific types of oils such as polyolester (POE) or polyvinyl ether (PVE). POE is a monomeric lubricant used in both non-HFC and HFC compressors, while PVE is a polymeric lubricant designed especially for HFC systems, where it may exhibit superior performance to POE in some cases. ${ }^{80}$ A separate Google Patents database search indicates the development of POE lubricants for refrigerator compressors was first disclosed in several patent applications filed by Carrier in the late 1980s and early 1990s, while the earliest PVE patents were issued to Idemitsu Corporation in the late 1980 s to mid-1990s. In addition to Idemitsu PVE oil's use in room airconditioner compressors, the main application driving its demand is its use in the automobile air-conditioning compressor market, where it controlled approximately $80 \%$ of the global market share as of 2013. ${ }^{81}$ An examination of several RAC catalogs and service manuals indicates that most, if not all, major RAC manufacturing companies use PVE lubricant in at least some of their rotary compressors. However, it is important to note that the original specifications of POE and PVE oil are insufficiently miscible with R-32 refrigerant. More-miscible POE and PVE oils have been developed and patented for use in R-32 compressors. ${ }^{82,83}$ 


\subsection{Release of Patents for Low-GWP Refrigerant Technology}

In 2015, Daikin released 93 patents related to R-32 inverter air-conditioning technology to be freely used by any manufacturer worldwide. ${ }^{84}$ These patents had been available in emerging markets before this release, and the goal of opening patents to all manufacturers was to foster additional adoption of R-32 as a low-GWP alternative to the conventional air-conditioning refrigerants R-22 and R-410A. Ingersoll Rand (manufacturer of the Trane brand) released patents related to the refrigerant $\mathrm{R}-452 \mathrm{~B}$, another $\mathrm{R}-410 \mathrm{~A}$ replacement, in $2016 .{ }^{85}$ Both of these highly publicized patent releases are strategic moves by companies that, in taking into account the impending refrigerant phaseouts called for by the Kigali Amendment, believe it will be more beneficial for them in the long run to foster more immediate and widespread adoption of their "chosen" low-GWP refrigerants by other manufacturers rather than rely on near-term profits generated from manufacturing patented technologies by themselves and marketing them to a narrower subset of the global market.

\subsection{Reciprocating Compressors and the Refrigerator Market}

The other major class of compressors used in residential applications are the hermetic reciprocating compressors typically used in household refrigerators. While reciprocating models are not the main focus of this report, it is worth noting some of the parallels between the rotary and reciprocating compressor markets. Reciprocating compressors, like their rotary counterparts, are available in both fixed- and variable-speed types, and most reciprocating compressor manufacturers now offer inverter models. There are several key differences between the markets, including the types of refrigerants used, the fraction of units that are variable-speed, and the charge quantities. HFC-134a is the refrigerant most commonly used in U.S. refrigerator models, while European and Japanese models typically use hydrocarbons. As shown in Figure 24 , only about $16 \%$ of the reciprocating compressors produced in China were variable-speed. China, Brazil, Europe, India, Thailand, and the United States are all major hubs of reciprocating compressor manufacturing; reciprocating compressor production is not as highly concentrated in China as is rotary compressor manufacturing. Household refrigerators also require with much smaller amounts of refrigerant than household air conditioners.

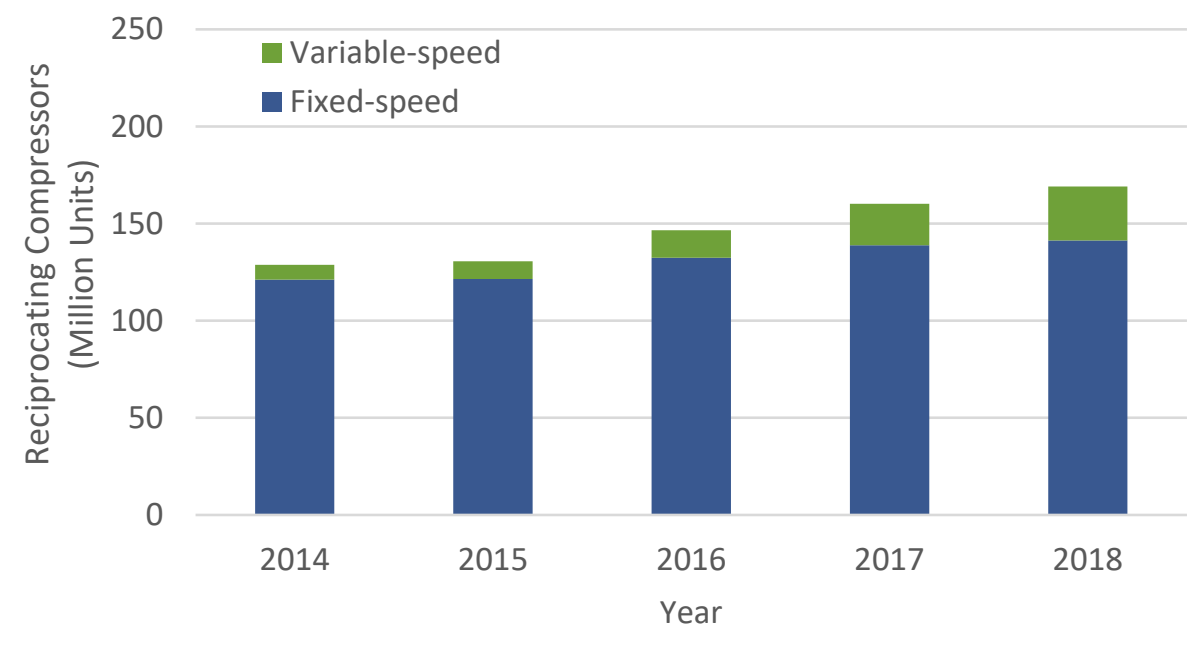

Figure 24. Sales of Chinese Fixed- and Variable-Speed Hermetic Reciprocating Compressors, 2014-2018 


\section{Lessons Learned: MLF Conversion Projects}

Under the terms of the Montreal Protocol, the Multilateral Fund for the Implementation of the Montreal Protocol (MLF) was established to help developing (Article 5) countries meet their phaseout targets for ozone-depleting substances. The MLF is funded by developed (non-Article 5) countries, and it has provided assistance to numerous Article 5 countries since its inception. Of particular interest in this analysis are the MLF projects involving the conversion of airconditioning production lines from a high-GWP, ozone-depleting refrigerant to one that is not ozone depleting and also has a lower GWP (e.g., HCFC-22 to HFC-32 or R-290). To date, several countries, including China, Thailand, Vietnam, and Indonesia have received MLF funding to complete such conversion projects. However, some of these projects have been more successful than others when measured by the resulting adoption of the new refrigerant technology in the local market. In this section, we provide an overview of these MLF projects and consider the factors leading to the varying levels of eventual success and remaining challenges.

\subsection{Indonesia}

In 2011, an MLF-funded project was proposed in which Panasonic and Daikin would initiate the conversion of Indonesia's R-22 RAC lines to R-32 technology. This refrigerant was chosen because the infrastructure for R-32 compressors, such as the availability of technicians experienced with its mild flammability, was already in place. Panasonic was the only RAC manufacturer in Indonesia, but it accounted for only $22 \%$ of the local market; the remaining $78 \%$ of the RAC demand was met by imported units.

Being some of the first MLF undertakings of this nature, Indonesia's RAC conversion projects have encountered some challenges, both economic and technical. After the conversion process concluded, production had not yet begun at some Indonesian RAC plants because of a lack of market demand and essential components. ${ }^{86}$ Unlike fellow RAC manufacturing hubs China and Thailand, Indonesia does not have any domestic compressor production. Local RAC manufacturers rely exclusively on imported compressors, and Panasonic's converted R-32 lines are no exception. Indonesia has faced a shortage of R-32 compressors, especially the highercapacity units used in the commercial sector. MLF documents point to a possible cause for this supply chain holdup-a new Chinese flammability standard: GB/T9237-2017. The United Nations Development Programme indicated that large-scale production of R-32 compressors in China might have been delayed until after the updated flammability standard went into effect (which it did in July 2018). It also emphasized that other factors, such as public perception of safety, energy efficiency, and reliability, are driving the eventual market adoption of R-32 units in Indonesia. ${ }^{87}$

As discussed in Section 5.3, both R-32 compressor and R-32 RAC unit production in China have ramped up significantly year-over-year at the monthly level. Domestic sales of R-32 compressors and RAC units have accounted for most of this increase; Chinese exports of R-32 units have not risen at nearly the same rate. Unless Chinese R-32 compressor production continues to ramp up significantly and outpaces rising internal demand, export levels may remain low and Indonesia may continue to have problems sourcing R-32 compressors for its own converted RAC lines. 
Despite the challenges, there are several potential future avenues of expansion for the R-32 RAC market in Indonesia. In 2014, a Daikin representative stated that if room air-conditioning unit sales in Indonesia rose significantly, the company would consider migrating RAC capacity from one of their factories in Thailand to Indonesia. ${ }^{88}$ And while no such capacity transfers have yet occurred to date, Daikin did open a technician training center in Jakarta in May $2018 .{ }^{89}$

\subsection{Thailand}

In an MLF conversion project in Thailand, Daikin worked with local RAC manufacturers to convert R-22 lines to R-32. The project was largely successful, as evidenced by the now robust local market for R-32 RAC units. R-32 is a mildly flammable refrigerant that is subject to charge restrictions. A key factor in the success of this conversion project was the updating of building safety regulations to allow the installation of R-32 units, including in high-rise apartment buildings. Another key driver was Daikin's extensive public awareness campaign aimed at providing information to the Thai population about the safety and efficiency aspects of R-32 units. Daikin also led technician training programs to ensure long-term competence in the local RAC servicing sector. ${ }^{86}$

The Thai R-32 conversion program was not without challenges of its own, however. The updated building standard allows RAC units with capacity up to 53,500 BTU/hr, but it was initially unclear whether the sizes of R-32 compressors available would be able to handle the larger cooling applications. Solving this lack of availability of R-32 compressors in the upper capacity ranges required coordination between multiple suppliers who may have previously refrained from discussing the available sizes of such compressors for fear of losing market advantages. 86,90

\subsection{China}

With MLF funding, Midea and other Chinese RAC manufacturers converted several airconditioner production lines from R-22 to R-290 under Stage I of China's HCFC phaseout management plan. However, there has not been much demand for these new R-290 RAC units since the completion of the line conversions, and several of the converted production lines are now idled. The growing demand for high-efficiency inverter compressors and the phaseout of R-22 may create an unintended incentive for companies to expand production of high-GWP units by adding R-410A inverter production, while the R-290 lines remain idle.

One potential cause for the lack of widespread R-290 market adoption is the fact that R-290 is a highly flammable refrigerant. Current building safety codes typically restrict the charge limits of highly flammable chemicals to levels that most residential systems would exceed. Some in the industry have noted that lower-flammability refrigerants like R-32 are subject to different safety code restrictions and in some cases may be grouped with non-flammable refrigerants, whereas that is never the case with R-290. Organizations such as the International Electrotechnical Commission have made progress on updating building codes to be more accommodating of R-290 units, but the review process is still ongoing in some cases. Figure 25 shows the annual production, sales, and exports of Chinese-made R-290 rotary compressors. While significant year-over-year growth is not as apparent as it is for R-32 compressors in Figure 26, a slight uptick in production and exports compared to prior years is evident for some of the last few months of 2018. 

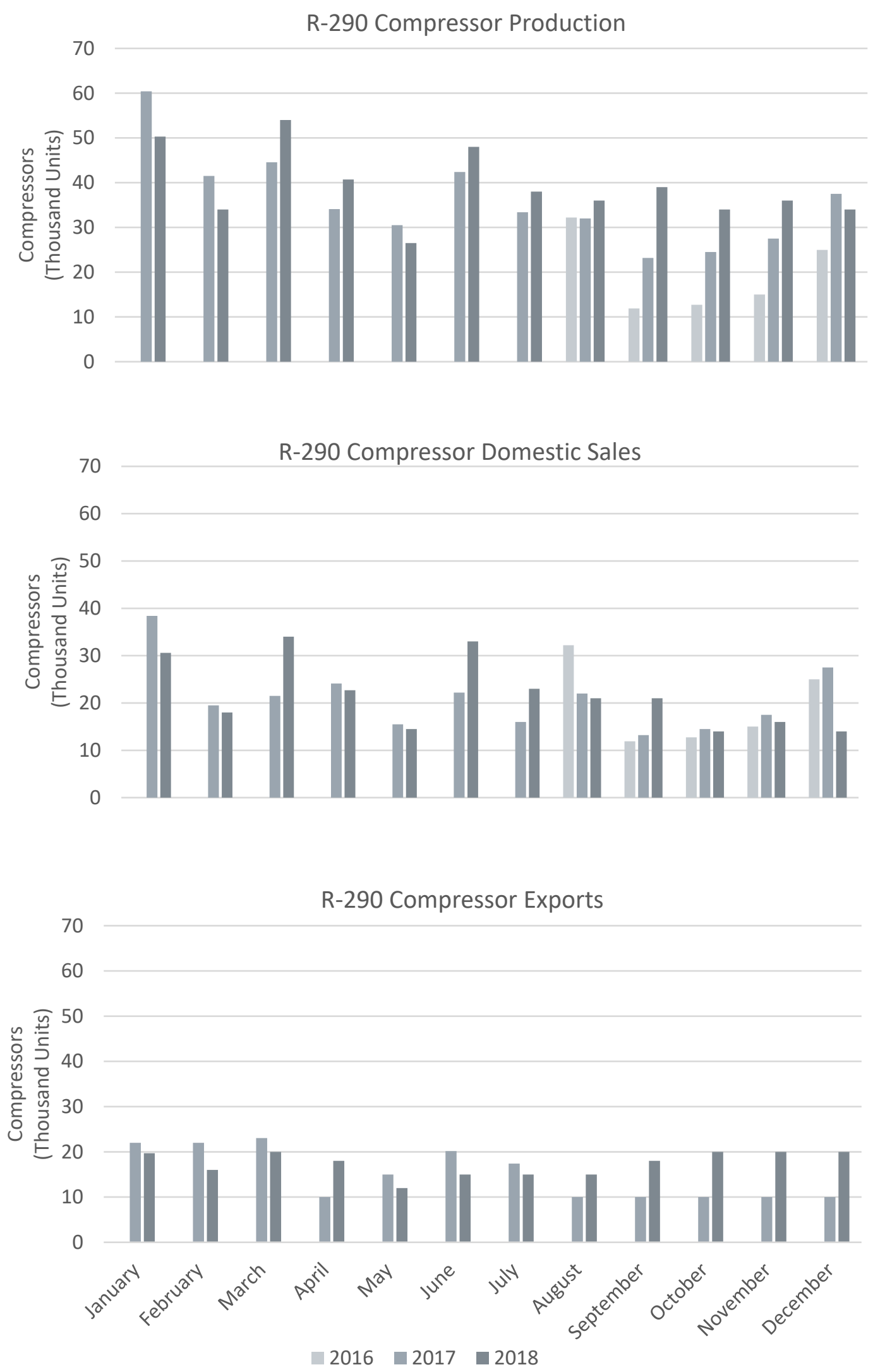

Figure 25. Monthly Chinese production and distribution of R-290 rotary compressors, 2016-2018 


\section{R-32 Compressor Production}

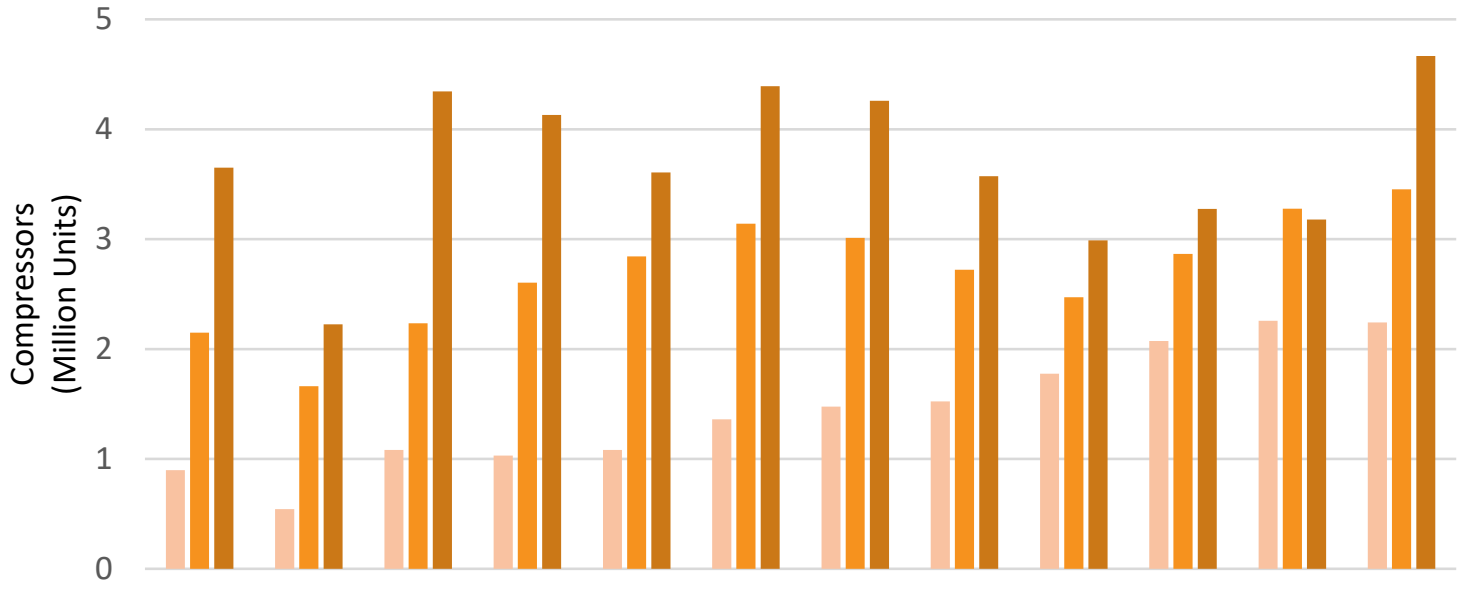

\section{R-32 Compressor Domestic Sales}

5

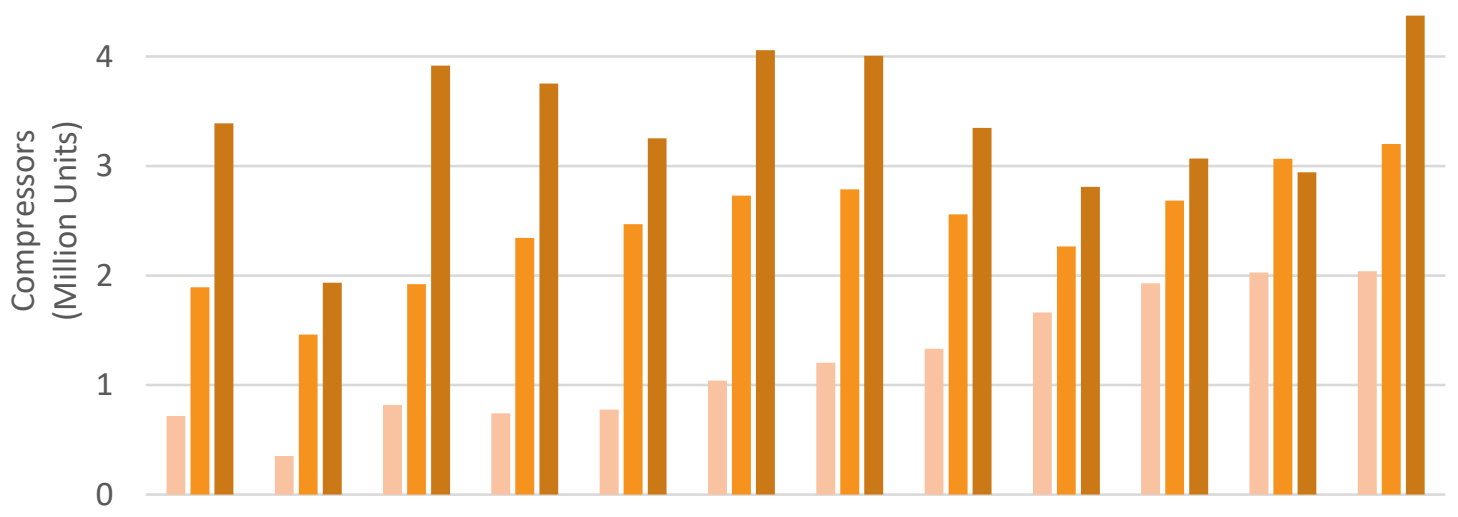

R-32 Compressor Exports

5

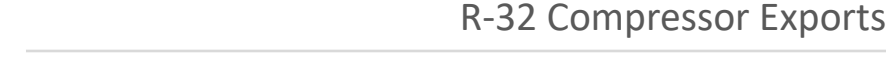

4

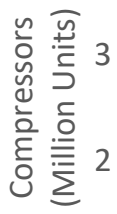

1

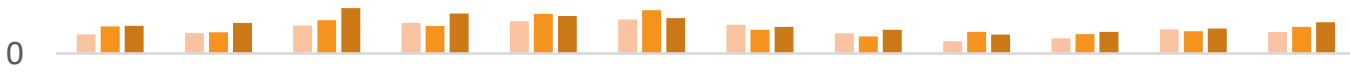

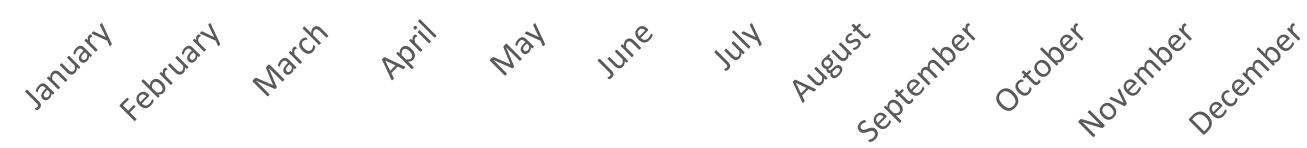

- $2016 \square 2017 \square 2018$

Figure 26. Monthly Chinese production and distribution of R-32 rotary compressors, 2016-2018 


\subsection{Vietnam}

Vietnam is also in the process of converting R-22 lines to low-GWP refrigerant technology via the MLF. In a recent development regarding the refrigerant of choice, Midea requested that the original MLF conversion plan to convert from R-22 to R-290 be modified so that the company may instead convert to R-32 lines in Vietnam. To justify this change, Midea cited a need to develop a more diverse refrigerant portfolio to serve several different markets. ${ }^{87}$

GMCC, Midea's compressor-supplying subsidiary in China, offers both R-290 and R-32 models, so Midea would not be expected to face a shortage of compressors for its converted Vietnamese RAC manufacturing, regardless of the refrigerant chosen. MLF documents show that Midea recognizes the growing market presence of Daikin in Vietnam and is anticipating growth in R-32 acceptance and adoption in this country. ${ }^{87}$ In its 2017 annual report, Daikin highlighted its attention on Vietnam in the Southeast Asian market: "Daikin will strengthen its lineup of air-conditioning inverters, and launch new residential multi-air units to meet the needs of middle-class consumers in Vietnam and Thailand". ${ }^{91}$ Daikin also opened a new RAC manufacturing plant in Vietnam in May 2018, with a planned capacity of one million units per year by $2020 .^{92}$ Midea will look to leverage this existing R-32 infrastructure and know-how to compete in Vietnam once the manufacturing line conversions are complete. 


\section{Conclusion}

This report analyzed the market for compressors used in room air conditioning applications worldwide. Most of these compressors are manufactured in Asia-specifically, China. Manufacturers offer compressors in a variety of refrigerants as well as cooling capacity sizes. Low-GWP refrigerant models utilizing R-32 or R-290 are offered by some compressor manufacturers, and the fraction of compressors coming onto the market which use these newer refrigerants is growing, at least in China. This report also provides a visualization of global trade patterns for the room air-conditioning compressors supply chain; most compressor trade originates in China, Japan, South Korea, and Thailand for markets in Europe, India, and other countries. More rigorous trade flow analysis of air-conditioning compressors and their parts (such as comparing variable-speed vs. fixed-speed trade flows) would yield interesting, actionable insights but would also require a level of resolution not currently reported in country-level trade flow datasets.

This report also covers the history and present role of intellectual property for the growing inverter-driven compressor market, identifying companies such as Toshiba, Daikin, LG, and Samsung which have made significant research and development efforts in this area, as well as companies like Idemitsu, which has a large presence in the lubricant sector, a critical part of the compressor supply chain. Lastly, we consider the results of past or ongoing MLF-funded manufacturing line conversion projects in Indonesia, Thailand, China, and Vietnam and identify key attributes of successful market adoption (e.g., public awareness campaigns) as well as challenges to adoption (e.g., high-capacity R-32 compressor sourcing or R-290 flammability concerns pertaining to building safety code updates). The end goal of this report is to inform the discussion around efforts to transition the global residential air conditioning sector toward more energy-efficient cooling equipment utilizing lower-GWP refrigerants. 


\section{References}

1. Ozone Secretariat. The Kigali Amendment (2016): The Amendment to the Montreal Protocol Agreed by the Twenty-Eighth Meeting of the Parties (Kigali, 10-15 October 2016). Treaties (2016). http://ozone.unep.org/en/handbook-montreal-protocol-substancesdeplete-ozone-layer/41453. (Accessed September 24, 2018)

2. McNeil, M. A. \& Letschert, V. E. Future Air Conditioning Energy Consumption in Developing Countries and What Can be Done about It: The Potential of Efficiency in the Residential Sector. (2008).

3. Velders, G. J. M., Fahey, D. W., Daniel, J. S., McFarland, M. \& Andersen, S. O. The Large Contribution of Projected HFC Emissions to Future Climate Forcing. PNAS 106, 1094910954 (2009).

4. Environmental Protection Agency. Transitioning to Low-GWP Alternatives in Residential \& Light Commercial Air Conditioning. (2015). https://www.epa.gov/sites/production/files/2015-

09/documents/epa_hfc_residential_light_commercial_ac.pdf. (Accessed April 22, 2019)

5. Won Young Park, Nihar Shah \& Brian Gerke. Assessment of Commercially Available EnergyEfficient Room Air Conditioners Including Models with Low Global Warming Potential (GWP) Refrigerants. Lawrence Berkeley National Laboratory (2017). http://www.osti.gov/servlets/purl/1408468/ (Accessed March 26, 2019)

6. EN DataCenter. ChinalOL (2018). http://data.chinaiol.com/ECData?iid=12. (Accessed September 23, 2018)

7. GMCC \& Welling. About Us [Translated]. http://www.gmcc-welling.com/us/3.html. (Accessed September 23, 2018)

8. GMCC Completes 70 Millionth Compressor in Its Wuhu Factory. Japan Air Conditioning, Heating \& Refrigeration News (2017). http://www.ejarn.com/detail.php?id=45244. (Accessed September 23, 2018)

9. GMCC \& Welling. Rotary Compressor 2018. http://www.gmccwelling.com/Public/upload/service/dow/13/363f0b096fc68367a595e61bc2cf3a09.pdf. (Accessed September 21, 2018)

10. Meizhi's Air-Conditioner Compressor Exports in January-May Increased by $31.4 \%$ Year-onYear [Translated]. ChinalOL (2015). http://bao.hvacr.cn/201507_2059185.html. (Accessed September 22, 2018)

11. GMCC \& Welling. GMCC R290 DC Inverter Air Conditioner Compressor is Shipped Overseas [Translated]. (2016). http://www.gmcc-welling.com/Home/News/detail/id/219.html. (Accessed September 23, 2018) 
12. World Compressor Market: 2 Rotary. Japan Air Conditioning, Heating \& Refrigeration News (2018). https://www.ejarn.com/detail.php?id=50253\&Iid=. (Accessed September 22, 2018)

13. Zhuhai Lingda Compressor Co., Ltd. About Lingda [Translated]. (2012). http://www.landa.com.cn/about/index.aspx?MenuID=02010201. (Accessed September 22, 2018)

14. Dan Zhou. Rotary Compressor Manufacturing: Lingda China Factory [Translated]. ChinalOL (2016). http://acc.chinaiol.com/xzysj/q/0205/41164777.html. (Accessed September 22, 2018)

15. Zhuhai Lingda Compressor Co., Ltd. All Products [Translated]. (2012). http://www.landa.com.cn/product/allpro.aspx. (Accessed December 10, 2018)

16. Gree. Global Production Bases. (2016). http://global.gree.com/ywb/globalnetwork/gree_brand_strategic_partners/index.shtml. (Accessed September 22, 2018)

17. Peng Yanfeng \& Mo Yelin. Air Conditioner Firm's Plan to Develop Chips is Hot Air, Observers Say. Caixin Global (2018). https://www.caixinglobal.com/2018-08-23/air-conditioner-firmsplan-to-develop-microchips-is-just-hot-air-observers-say-101318085.html. (Accessed September 22, 2018)

18. Shanghai Highly Electrical Appliances Co., Ltd. Annual Report 2017 (Abstract). (2018). http://www.highly.cc/upload/Report/2018041302064615.pdf (Accessed September 21, 2018)

19. Shanghai Highly Electrical Appliances Co., Ltd. Highly Catalogue 2018. (2018).

20. Li Zhang (Personal Communication). (2018).

21. Rechi Precision Co., Ltd. Investor Conference. (2018). http://www.rechi.com/image/en/invest/2018\%20rechi\%20presentation_v2.pdf. (Accessed May 15, 2019)

22. Rechi Precision Co., Ltd. Rotary Compressor. (2011). http://www.rechi.com/en/webProductsEN.do?method=getCompressor. (Accessed February 7, 2019)

23. Quality is the Life: A Visit Report of Panasonic Wanbao Compressor. Japan Air Conditioning, Heating \& Refrigeration News (2009). http://www.ejarn.com/detail.php?id=11746\&l_id=. (Accessed September 22, 2018)

24. Panasonic Wanbao (Guangzhou) Compressor Co., Ltd. Product Brochure of Panasonic Wanbao Appliances Compressor (Guangzhou). (2018). https://industrial.panasonic.com/cdbs/www-data/pdf/ADL0000/ADL0000COL1.pdf (Accessed February 7, 2019) 
25. LG. Rotary Compressor for Air Conditioning. (2010). http://www.prattco.com/pdf/Compressors/LG\%20Rotary\%20Catalog.pdf. (Accessed May 15, 2019)

26. LG. Rotary \& Scroll Compressor. (2015). http://www.lg.com/global/business/download/resources/cm/Aircon_Compressor_1207.pdf. (Accessed May 15, 2019)

27. Mitsubishi Electric. Mitsubishi Electric (Guangzhou) Compressor Co. [Translated]. (2016). http://www.mgc.com.cn/. (Accessed September 22, 2018)

28. Samsung. Rotary Compressor. Samsung Compressor, A Leader For Decades (2018). https://www.samsung.com/global/business/compressor/ourbusiness/rotary-compressor/. (Accessed September 22, 2018)

29. Samsung. Samsung Compressor. (2018). https://images.samsung.com/is/content/samsung/p5/global/business/compressor/rotarycompressor/all-rotary-compressor/SAMSUNG-Compressor-Catalogue-2018.pdf. (Accessed February 7, 2019)

30. China Daily. China Resource \& Sanyo Compressor (Shenyang) Co. Invest in Shenyang (2016). http://www.chinadaily.com.cn/m/liaoning/investinshenyang/201609/05/content_18539105.htm. (Accessed September 22, 2018)

31. Xi' an Qingan Refrigeration Equipment Co., Ltd. Company Profile: Enterprise Overview [Translated]. (2008). http://www.qing-an.com/about.asp. (Accessed September 22, 2018)

32. Galanz Expands AC Compressor Production Capacity. Japan Air Conditioning, Heating \& Refrigeration News (2013). http://www.ejarn.com/detail.php?id=23700\&l_id=. (Accessed September 22, 2018)

33. Jiangsu Chunlan Import \& Export Co., Ltd. Rotary Compressor. Alibaba.com https://www.alibaba.com/product-detail/Rotary-Compressor_60238985123.html. (Accessed September 22, 2018)

34. Chigo Celebrates Production of the 1 Millionth Compressor. Japan Air Conditioning, Heating \& Refrigeration News (2015). http://www.ejarn.com/detail.php?id=37782\&l_id=. (Accessed September 22, 2018)

35. Chigo's 5 Millionth Compressor Rolls off Production Line. Japan Air Conditioning, Heating \& Refrigeration News (2018). http://www.ejarn.com/detail.php?id=49715\&l_id=. (Accessed September 22, 2018)

36. Daikin Industries, Ltd. Annual Report 2014. (2014). http://www.annualreports.com/HostedData/AnnualReportArchive/d/OTC_DKILF_2014.pdf. (Accessed May 15, 2019) 
37. Watchiranont Thongtep. Daikin Grows Home and Abroad. The Nation (2016). http://www.nationmultimedia.com/detail/Corporate/30291094. (September 22, 2018)

38. Compressor World Trends By Compressor Types: 2. Rotary Compressors. Japan Air Conditioning, Heating \& Refrigeration News (2003). https://www.ejarn.com/detail.php?id=12086\&l_id=1. (Accessed September 22, 2018)

39. Daikin launches new R32 unit in Thailand. Cooling Post (2015). https://www.coolingpost.com/world-news/daikin-launches-new-r32-unit-in-thailand/. (Accessed February 22, 2019)

40. Siam Compressor Industry Co., Ltd. About Us - Corporate profile. (2017). https://siamcompressor.com/index.php/corporate-profile. (Accessed September 22, 2018)

41. SCI Focusing on BLDC Inverter Scroll Compressors. Japan Air Conditioning, Heating \& Refrigeration News (2010). http://www.ejarn.com/detail.php?id=13169\&I_id=. (Accessed September 22, 2018)

42. Siam Compressor Industry Co., Ltd. Rotary Compressor Catalogue. (2016). https://siamcompressor.com/index.php/downloads. (Accessed September 22, 2018)

43. Kulthorn Kirby Public Company, Ltd. Investor Relations. (2012). http://kkc.listedcompany.com/factsheet.html. (Accessed September 22, 2018)

44. Kulthorn Acquires Bristol to Expand Its Business. Japan Air Conditioning, Heating \& Refrigeration News (2018) https://www.ejarn.com/detail.php?id=55585. (Accessed January 10, 2019)

45. Toshiba Carrier and Fujitsu General Announce Joint Venture in Thailand to Manufacture Compressors. (2012). https://www.fujitsu-general.com/global/news/2012/12-V0217/index.html. (Accessed September 22, 2018)

46. By Compressor Types: 2. Rotary Compressors. Japan Air Conditioning, Heating \& Refrigeration News (2006). http://www.ejarn.com/detail.php?id=11842. (Accessed September 22, 2018)

47. Statistics - Japan. Japan Air Conditioning, Heating \& Refrigeration News (2017). http://www.ejarn.com/news_list.php?c=statistic\&t=JAPAN. (Accessed September 22, 2018)

48. Mitsubishi Electric Corporation. Advanced Technology of Air Conditioning Pursues: What is Invisible Comfort? [Translated]. The 2nd Shizuoka Prefecture Shizuoka Plant (2012). http://www.mitsubishielectric.co.jp/me/project/shizuoka/report.html. (Accessed September 22, 2018)

49. Ankur Sharma \& Amit Shah. Room Air Conditioners. Motilal Oswal. (2017). https://www.researchpool.com/download/?report_id=1293126 (Accessed February 22, 2019) 
50. The Energy and Resources Institute, Natural Resources Defense Council \& Institute for Governance \& Sustainable Development. Improving Air Conditioners in India. (2018). http://www.teriin.org/sites/default/files/2018-04/improving-air-conditioners-in-india.pdf (Accessed February 22, 2019)

51. Bureau of Energy Efficiency, Ministry of Power, Government of India. Search and Compare: BEE Star Labelled. https://beestarlabel.com/Home/Searchcompare. (Accessed September $22,2018)$

52. Highly India to Double A/C Compressor Capacity at Gujarat Plant. The Hindu BusinessLine (2015). https://www.thehindubusinessline.com/companies/highly-india-to-double-accompressor-capacity-at-gujarat-plant/article8008464.ece. (Accessed September 21, 2018)

53. Hitachi-Highly Group JV to expand production capacity of Gujarat plant. United News of India (2018). http://www.uniindia.com/hitachi-highly-group-jv-to-expand-productioncapacity-of-gujarat-plant/business-economy/news/1306470.html. (Accessed September 24, 2018)

54. Highly Electrical Appliances India. Compressor Series. (2014). http://www.highly.co.in/compressor-series.html. (Accessed September 21, 2018)

55. Tecumseh to Focus on Value-Added Products. Business Standard India (2011). https://www.business-standard.com/article/companies/tecumseh-to-focus-on-valueadded-products-111121600091_1.html. (Accessed September 21, 2018)

56. Tecumseh Products Company. Business Strategy: 2009 Investor Presentation. (2009). http://filecache.investorroom.com/ir1_tecumseh/76/download/Tecumseh\%20Investor\%20 Strategy\%20Presentation.pdf. (Accessed September 21, 2018)

57. Panasonic Wanbao (Guangzhou) Compressor Co., Ltd. About Us: Production Base Introduction. http://pwapcgz.panasonic.cn/About/ProductionBase. (Accessed September $22,2018)$

58. Panasonic Celebrates its 100 Millionth Compressor Production in Malaysia. Japan Air Conditioning, Heating \& Refrigeration News (2016). http://www.ejarn.com/detail.php?id=42562. (Accessed September 22, 2018)

59. Shigekichi Kouchiyama, Yoshikazu Amou \& Machio Amano. Air Conditioning Business in Brazil. Hitachi Review 58, (2009). http://www.hitachi.com/rev/pdf/2009/r2009_06_110.pdf (Accessed September 24, 2018)

60. BSRIA. World Air Conditioning Market Grows Thanks to Hot Spots. (2015). https://www.bsria.co.uk/news/article/world-air-conditioning-market-grows-thanks-to-hotspots/ (Accessed September 21, 2018)

61. Daikin Industries, Ltd. Establishment of AC Equipment Production Factory in Rapidly Expanding Brazil as a Daikin First in Latin America [Press Release]. http://www.daikin.com/press/2011/110428/index.html. (Accessed September 21, 2018) 
62. Colin Taylor, Eric Gibbs, \& Ana Maria Carreño. Technical and Economic Feasibility Study for a High Efficiency Compressor Market in Brazil. CLASP (2018).

https://storage.googleapis.com/clasp-siteattachments/ENG-2018-Technical-and-EconomicFeasibility-Study-for-a-High-Efficiency-Compressor-Market-in-Brazil.pdf (Accessed January 7, 2018)

63. Nelson Marquezelli. Speech to Chamber of Deputies (Transcript) [Translated]. National Congress of Brazil. Session: 159.3.52. June 30, 2005.

https://www.camara.leg.br/internet/sitaqweb/TextoHTML.asp?etapa=3\&nuSessao=159.3.5 $2.0 \&$ nuQuarto $=73 \&$ nuOrador $=1 \&$ nulnsercao $=48 \&$ dtHorarioQuarto=12:24 (Accessed February 22, 2018)

64. Tecumseh do Brazil. Rotary Compressors. (2017). https://www.tecumseh.com/ /media/South-America/Files/Catalogues/2017/English/Tabde-AplicaoCompressor-Rotativo.pdf (Accessed September 22, 2018)

65. Štěpán Kaděra. Creating Production Plans for the Selected Business. (Brno University of Technology, 2018). https://www.vutbr.cz/www_base/zav_prace_soubor_verejne.php?file_id=172180. (Accessed May 15, 2019)

66. Daikin Industries, Ltd. About Daikin. https://www.daikin.ie/en_gb/about/daikin-brand.html. (Accessed September 22, 2018)

67. Zuguang Gu, Lei Gu, Roland Eils, Matthias Schlesner \& Benedikt Brors. circlize Implements and enhances circular visualization in R. Bioinformatics 30, 2811-2812 (2014). https://doi.org/10.1093/bioinformatics/btu393

68. Intracen. Trade Map: Trade Statistics for International Business Development. (2018). https://www.trademap.org/Index.aspx. (Accessed March 21, 2018)

69. United States Trade Representative. USTR Issues Tariffs on Chinese Products in Response to Unfair Trade Practices [Press Release]. (2018). https://ustr.gov/about-us/policyoffices/press-office/press-releases/2018/june/ustr-issues-tariffs-chinese-products. (Accessed September 21, 2018)

70. Frances Hadfield, Yun Gao \& Edward Goetz. China's Retaliatory Tariffs on $\$ 60$ Billion in U.S. Goods: List of Affected HTS Subheadings. International Trade Law (2018). https://www.cmtradelaw.com/category/china-retaliatory-tariffs/. (Accessed September 23, 2018)

71. John Brew, Frances Hadfield, Spencer Toubia, Edward Goetz \& Cherie Walterman. Latest U.S. Trade Actions/Tariffs and Other Countries Retaliatory Measures. International Trade Law (2018). https://www.cmtradelaw.com/2018/06/latest-u-s-trade-actions-tariffs-andother-countries-retaliatory-measures/. (Accessed September 23, 2018) 
72. United States Trade Representative. Implementing Modification to Section 301 Action: China's Acts, Policies, and Practices Related to Technology Transfer, Intellectual Property, and Innovation. (2019). https://ustr.gov/sites/default/files/enforcement/301Investigations/ Implementing_Modification_to_Section_301_Action.pdf. (Accessed May 15, 2019)

73. International Trade Centre. Market Access Map. http://www.macmap.org/QuickSearch/FindTariff/FindTariffResults.aspx?product $=8414300$ 0\&country=699\&year=2018\&source $=1$ |ITC\&AVE=1. (Accessed September 22, 2018)

74. World Air Conditioner Market: 2.8 Middle East. Japan Air Conditioning, Heating \& Refrigeration News (2018). https://www.ejarn.com/detail.php?id=56075. (Accessed March 27, 2019)

75. Greg Mazurkiewicz. April 29, 2003: Bristol And Alessa Group Sign Distribution Agreement. Air Conditionign, Heating \& Rrefrigeration News (2003). https://www.achrnews.com/articles/101456-april-29-2003-bristol-and-alessa-group-signdistribution-agreement (Accessed September 24, 2018)

76. Classic (Zamil) Window Type (BRISTOL Comp.) 24000 BTU. (2 Tons) Heat \& Cool. http://mokyfat.com/en/classic-zamil-window-type-bristol-comp-24000-btu-2-tons-heatcool. (Accessed September 24, 2018)

77. Toshiba. World's First Household Inverter Air Conditioner. Toshiba Science Museum (2018). http://toshiba-mirai-kagakukan.jp/en/learn/history/ichigoki/1981aircon/index.htm. (Accessed September 22, 2018)

78. Google. Google Patents. (2018). https://patents.google.com.

79. Intellectual Property India. Indian Patent Advanced Search System (inPASS). (2016). http://ipindiaservices.gov.in/publicsearch. (Accessed September 22, 2018)

80. Tominaga, S., Tazaki, T. \& Hara, S. Various Performance Of Polyvinylether (PVE) Lubricants With HFC Refrigerants. Proceedings of the International Refrigeration and Air Conditioning Conference. (2002). https://docs.lib.purdue.edu/iracc/600/. (Accessed March 29, 2019)

81. Idemitsu Daphne Hermetic Oil. Japan Air Conditioning, Heating \& Refrigeration News (2013). https://www.ejarn.com/detail.php?id=26620. (Accessed January 11, 2019)

82. Takeshi Okido, Katsuya Takigawa \& Masanori Saito. Development of Refrigeration Oil for Use with R32. International Refrigeration and Air Conditioning Conference. (2014). https://docs.lib.purdue.edu/iracc/1454/. (Accessed March 29, 2019)

83. Tomoya Matsumoto \& Yasuhiro Kawaguchi. Development of PVE Refrigeration Lubricants for R32. International Refrigeration and Air Conditioning Conference. (2014). https://docs.lib.purdue.edu/iracc/1556/. (Accessed March 29, 2019) 
84. Daikin Gives Free Access to R32 Patents. Cooling Post (2015). https://www.coolingpost.com/world-news/daikin-gives-free-access-to-r32-patents/. (Accessed September 22, 2018)

85. Ingersoll Rand Backs R410A Alternative DR-55. Cooling Post (2016). https://www.coolingpost.com/world-news/ingersoll-rand-backs-r410A-alternative-dr-55/. (Accessed September 22, 2018)

86. United Nations Environment Programme. Final Report on The Evaluation of HCFC PhaseOut Projects in the Refrigeration and Air-Conditioning Manufacturing Sector. (2016). http://www.multilateralfund.org/77/English/1/7709.pdf (Accessed March 29, 2019)

87. United Nations Environment Programme. Status Reports and Reports on Projects with Specific Reporting Requirements. (2018). http://www.multilateralfund.org/81/English/1/8110.pdf (Accessed March 29, 2019)

88. Lona Olavia. 2017, Daikin Targets to Build Factories in Indonesia [Translated]. beritasatu.com (2014). http://www.beritasatu.com/ekonomi/223390-2017-daikintargetkan-bangun-pabrik-di-indonesia.html. (Accessed September 24, 2018)

89. Daikin Industries, Ltd. Grand Opening of PT. Daikin Airconditioning Indonesia National Training Center (NTC). https://www.daikin.co.id/news-and-articles/news/2018/grandopening-of-pt-daikin-airconditioning-indonesia-national-training-center-ntc/. (Accessed September 24, 2018)

90. Junchaya, T. Introduction of Alternative Refrigerant in the Thailand Air Conditioning Sector. (2018). International Conference on Sustainable Cooling Conference. World Bank Group. November 28-30, 2018. http://esmap.org/sites/default/files/eventsfiles/Int\%20Conf\%20Sust\%20Cooling/Thanavat-\%20WB_ThaiAC\%26R32COOL\%20181129.pdf (Accessed March 29, 2019)

91. Daikin Industries, Ltd. Annual Report 2017. (2017). https://www.daikin.com/investor/data/report/daikin_jar17.pdf. (Accessed May 15, 2019)

92. Daikin Vietnam. Daikin Officially Opens the Air-Conditioning Factory in Vietnam. Daikin Vietnam (2018). http://www.daikin.com.vn/en/news/2018/daikin-officially-opens-the-airconditioning-factory-in-vietnam. (Accessed September 24, 2018) 


\section{Appendix A. Location and Capacity of Compressor Plants}

Table A-1. Location and Capacity of Compressor Plants, Ordered by Capacity

\begin{tabular}{|c|c|c|c|c|c|}
\hline Company & Factory Name & City, Country & Latitude & Longitude & $\begin{array}{l}\text { Estimated } \\
\text { Capacity } \\
\text { (Million } \\
\text { Units/yr) }\end{array}$ \\
\hline GMCC & $\begin{array}{l}\text { Guangdong Meizhi Precision Manufacturing Co., } \\
\text { Ltd. }\end{array}$ & Shunde, Guangdong, China & 22.77 & 113.33 & 44 \\
\hline Gree (Landa) & Zhuhai & Wuhu, Anhui, China & 22.24 & 113.56 & 27 \\
\hline GMCC & Anhui Meizhi Precision Manufacturing Co., Ltd. & Zhuhai, China & 31.46 & 118.41 & 17 \\
\hline Panasonic & $\begin{array}{l}\text { Panasonic Wanbao (Guangzhou) Compressor } \\
\text { Co., Ltd. }\end{array}$ & Guangzhou, China & 23.00 & 113.30 & 12 \\
\hline $\begin{array}{l}\text { Shanghai Highly } \\
\text { Electrical Company } \\
\text { (Highly) }\end{array}$ & Shanghai & Shanghai, China & 31.26 & 121.63 & 10.3 \\
\hline LG & Tianjin Factory & Tianjin, China & 39.22 & 117.21 & 9 \\
\hline Rechi & Qingdao factory & Qingdao, China & 36.00 & 120.16 & 9 \\
\hline Mitsubishi & $\begin{array}{l}\text { Mitsubishi Electric Guangzhou Compressor Co., } \\
\text { Ltd. }\end{array}$ & Guangzhou, China & 23.06 & 113.52 & 8 \\
\hline Samsung & Suzhou & Suzhou, China & 31.34 & 120.74 & 8 \\
\hline $\begin{array}{l}\text { Shanghai Highly } \\
\text { Electrical Company } \\
\text { (Highly) }\end{array}$ & Nanchang Highly & Nanchang, China & 28.76 & 115.89 & 6.2 \\
\hline Gree (Landa) & Hefei Landa Compressor Co., Ltd. & Hefei, China & 31.79 & 117.17 & 6 \\
\hline Rechi & DynaRechi & Jiujiang, China & 29.73 & 115.87 & 6 \\
\hline Rechi & TCL Rechi & Huizhou, China & 23.04 & 114.36 & 6 \\
\hline LG & Changwon Factory (HQ) & Changwon, Korea & 35.21 & 128.67 & 5.5 \\
\hline Qing'an & Xi'an Qing'an Refrigeration Equipment Co., Ltd. & Xi'an, China & 34.24 & 108.90 & 5 \\
\hline Gree (Landa) & Zhengzhou Landa Compressor Co., Ltd. & Zhengzhou, China & 34.82 & 113.51 & 4.5 \\
\hline Gree (Landa) & Wuhan Landa Compressor Co, Ltd. & Wuhan, China & 30.47 & 114.07 & 4.5 \\
\hline
\end{tabular}

A-1 


\begin{tabular}{|c|c|c|c|c|c|}
\hline Company & Factory Name & City, Country & Latitude & Longitude & $\begin{array}{l}\text { (Million } \\
\text { Units/yr) }\end{array}$ \\
\hline Gree (Landa) & Chongqing Landa Compressor Co, Ltd. & Chongqing, China & 29.51 & 106.45 & 4.5 \\
\hline Mitsubishi & Siam Compressor Industry Co., Ltd. & Chon Buri, Thailand & 13.09 & 100.91 & 4.09 \\
\hline Galanz & Zhongshan & Zhongshan, China & 22.69 & 113.38 & 3.6 \\
\hline Daikin & Daikin Compressor Industries, Ltd. & Rayong, Thailand & 12.98 & 101.11 & 3.5 \\
\hline Panasonic & Panasonic Appliances Air Conditioning Malaysia & Shah Alam, Malaysia & 3.05 & 101.55 & 3.5 \\
\hline LG & Rayong Factory & Rayong, Thailand & 13.02 & 101.20 & 3 \\
\hline Chunlan & Jiangsu & Jiangsu, China & 32.49 & 119.88 & 3 \\
\hline $\begin{array}{l}\text { Shanghai Highly } \\
\text { Electrical Company } \\
\text { (Highly) }\end{array}$ & Highly India & Changodar, India & 22.89 & 72.41 & 2 \\
\hline Chigo & Guangdong Chigo Air Conditioning Co., Ltd. & Guangdong, China & 23.20 & 113.18 & 2 \\
\hline $\begin{array}{l}\text { Shanghai Highly } \\
\text { Electrical Company } \\
\text { (Highly) }\end{array}$ & Mianyang Highly & Mianyang, China & 31.46 & 104.70 & 1.5 \\
\hline Tecumseh & Tecumseh do Brazil & Sao Carlos, Brazil & -22.03 & -47.89 & 1.5 \\
\hline Daikin & Daikin Device (Suzhou) Co., Ltd & Suzhou, China & 31.33 & 120.79 & 1.5 \\
\hline Mitsubishi & Mitsubishi Shizuoka Works & Shizuoka, Japan & 34.97 & 138.42 & 1.2 \\
\hline Kulthorn Kirby & Kulthorn Kirby Public Company Limited & Bangkok, Thailand & 13.77 & 100.79 & 1 \\
\hline Tecumseh & Balanagar (Tecumseh India) & Hyderabad, India & 17.48 & 78.45 & 1 \\
\hline THACOM & Thai Compressor Manufacturing Co., Ltd. & Chachoengsao, Thailand & 13.78 & 100.97 & 1 \\
\hline Bristol & Bristol Compressors International, LLC & Bristol, Virginia, United States & 34.99 & 135.98 & 1 \\
\hline Daikin & Shiga & Shiga, Japan & 34.57 & 135.42 & 1 \\
\hline Daikin & Rinkai & Sakai, Japan & 49.17 & 16.67 & 1 \\
\hline Daikin & Daikin Device Czech Republic & Brno, Czech Republic & 13.42 & 101.01 & 0.79 \\
\hline Daikin & Daikin Industries Thailand & Chonburi, Thailand & 13.78 & 100.97 & 0.5 \\
\hline
\end{tabular}

\section{A-2}




\section{Appendix B. 2017 Compressor Trade Flows}

Table B-1. Compressor Trade Flow Data for 2017

\begin{tabular}{|c|c|c|c|c|c|c|c|c|c|c|c|c|c|}
\hline $\begin{array}{c}\text { Exporter } \rightarrow \\
\text { Importer } \downarrow\end{array}$ & Africa & Brazil & China & Europe & India & Japan & Malaysia & $\begin{array}{l}\text { Middle } \\
\text { East }\end{array}$ & S. Korea & Thailand & $\begin{array}{l}\text { United } \\
\text { States }\end{array}$ & Other & $\begin{array}{l}\text { Total } \\
\text { Imports }\end{array}$ \\
\hline Africa & - & - & 1.03 & - & 0.11 & 0.04 & 0.02 & - & 0.01 & 0.11 & 0.01 & - & 1.32 \\
\hline Brazil & - & - & 1.55 & - & $<0.01$ & 0.12 & $<0.01$ & - & 0.23 & 0.08 & 0.02 & - & 2.00 \\
\hline China & - & - & - & $<0.01$ & 0.04 & 0.15 & 0.04 & - & 0.16 & 1.77 & $<0.01$ & - & 2.17 \\
\hline Europe & - & - & 3.07 & - & 0.01 & 0.11 & 0.12 & - & - & 0.37 & 0.07 & - & 3.75 \\
\hline India & - & - & 4.08 & $<0.01$ & - & 0.00 & 0.01 & - & 0.30 & 0.40 & $<0.01$ & - & 4.77 \\
\hline Japan & - & - & 2.61 & - & 0.00 & - & 0.15 & - & $<0.01$ & 0.91 & 0.02 & - & 3.69 \\
\hline Malaysia & - & - & 1.17 & - & 0.00 & 0.02 & - & - & 0.01 & 0.21 & $<0.01$ & - & 1.41 \\
\hline Middle East & - & - & 0.67 & 0.01 & 0.14 & 0.00 & 0.15 & - & - & 0.29 & 0.35 & - & 1.62 \\
\hline S. Korea & - & - & 2.22 & - & 0.10 & 0.02 & 0.01 & - & - & 0.66 & 0.02 & - & 3.02 \\
\hline Thailand & - & - & 4.71 & $<0.01$ & $<0.01$ & 0.26 & 0.21 & - & 1.54 & - & $<0.01$ & - & 6.71 \\
\hline $\begin{array}{l}\text { United } \\
\text { States }\end{array}$ & - & - & 1.50 & - & - & 0.03 & 0.47 & - & 0.14 & 0.46 & - & - & 2.61 \\
\hline Other & - & - & 5.65 & 0.01 & 0.22 & 0.29 & 0.75 & - & 0.60 & 1.21 & 0.28 & - & 9.00 \\
\hline $\begin{array}{r}\text { Total } \\
\text { Exports }\end{array}$ & - & - & 28.25 & 0.02 & 0.63 & 1.03 & 1.92 & - & 2.98 & 6.47 & 0.77 & - & \\
\hline
\end{tabular}

Data in are in millions of units.

Sources: Trade Map ${ }^{68}$ and CEMAC analysis 